\section{$3 \mathrm{Ji} \mathrm{Li}^{1,{ }^{*},}$, Daoxian Yuan ${ }^{1,2}$, Fuxi Zhang ${ }^{3}$, Yongjun Jiang ${ }^{1}$, Jiao Liu ${ }^{4}$, Mingguo Ma ${ }^{1}$}

$4 \quad{ }^{1}$ Chongqing Jinfo Mountain Karst Ecosystem National Observation and Research

5 Station, Chongqing Key Laboratory of Karst Environment, School of Geographical

6 Sciences, Southwest University, Chongqing 400715, China

$7 \quad{ }^{2}$ Karst Dynamic Laboratory, Ministry of Land and Resources, Guilin 541004, China

$8 \quad{ }^{3}$ College of Engineering Science and Technology, Shanghai Ocean University;

9 Shanghai Engineering Research Center of Marine Renewable Energy 201306, China

$10{ }^{4}$ Chongqing municipal hydrological monitoring station, Chongqing 401120, China

11 Corresponding author: Ji Li (445776649@qq.com)

Abstract Karst trough valleys are prone to flooding, primarily because of the unique hydrogeological features of karst landform, which are conducive to the spread of rapid runoff. Hydrological models that represent the complicated hydrological processes in karst regions are effective for predicting karst flooding, but their application has been hampered by their complex model structures and associated parameter set, especially so for distributed hydrological models, which require large amounts of hydrogeological data. Distributed hydrological models for predicting the Karst flooding is highly dependent on distributed structrues modeling, complicated boundary parameters setting, and tremendous hydrogeological data processing that is both time and computational power consuming. Proposed here is a distributed physically-based karst hydrological model, known as the QMG (Qingmuguan) model. The structural design of this model is relatively simple, and it is 
generally divided into surface and underground double-layered structures. The parameters that represent the structural functions of each layer have clear physical meanings, and the parameters are less than those of the current distributed models. This allows modeling in karst areas with only a small amount of necessary hydrogeological data. 18 flood processes across the karst underground river in the Qingmuguan karst trough valley are simulated by the QMG model, and the simulated values agree well with observations, for which the average value of Nash-Sutcliffe coefficient was 0.92 . A sensitivity analysis shows that the infiltration coefficient, permeability coefficient, and rock porosity are the parameters that require the most attention in model calibration and optimization. The improved predictability of karst flooding by the proposed QMG model promotes a better mechanistic depicting of runoff generation and confluence in karst trough valleys.

Keywords: Simulation and forecasting of karst floods; Karst trough valleys; QMG (Qingmuguan) model; Parametric optimization; Parameter sensitivity analysis

\section{Introduction}

Karst trough valleys are very common in China, especially in the southwest. In general, these karst areas are water scarce because their surfaces store very little rainfall, but it is also a protential birthplace for floods. Because trough and valley landforms and topographic features facilitate the formation and propagation of floods ( $\mathrm{Li}$ et al., 2021). Taking the study area, the Qingmuguan karst trough valley for example, floods used to happen here constantly. In recent years, with the increase in extreme rainfall events and the increased area of construction land in the region, rainfall infiltration decreased as long as rapid runoff over impervious surfaces increased that results in frequent catastrophic flooding in the basin (Liu et al., 2009). Excess water overflows from karst sinkholes and underground river outlets often occur during floods, flooding large areas of farmland and residential areas and causing serious economic losses (Yu et al., 2020). Therefore, the simulation and prediction 
of karst flooding events in these karst trough valleys like the study area are both important and urgently needed.

Hydrological models can be effective for forecasting floods and evaluating water resources in karst areas (Ford and Williams, 2007; Williams, 2009). However, modeling floods in karst regions is extremely difficult because of the complex hydrogeological structure. Karst water-bearing systems consist of multiple media under the influence of complex karst development dynamics (Worthington et al., 2000; Kovács and Perrochet, 2008), such as karst caves, conduits, fissures, and pores, and are usually highly spatially heterogeneous (Chang and Liu, 2015; Mario et al., 2019). In addition, the intricate surface hydrogeological conditions and the hydrodynamic conditions inside the karst water-bearing medium result in significant temporal and spatial differences in the hydrological processes in karst areas (Geyer et al., 2008; Bittner et al., 2020).

Early studies on flood forecasting in karst regions, with simplified lumped hydrological models , were commonly used to describe the rainfall-discharge relationship (e.g., Kovács and Sauter, 2007; Fleury et al., 2007b; Jukić and Denić, 2009; Hartmann et al., 2014a). With the development of physical exploration technology and the progress made in mathematics, computing, and other interdisciplinary disciplines, the level of modeling has gradually improved (Hartmann and Baker, 2017; Hartmann, 2018; Petrie et al., 2021). Distributed hydrological models have subsequently become widely used in karst areas. The main difference between the lumped and distributed hydrological models is that the latter divide the entire basin into many sub-basins to calculate the runoff generation and confluence, thereby better describing the physical properties of the hydrological processes inside the karst water-bearing system (Hartmann, 2018; Epting et al., 2018).

Because of their simple structure and little demand for modeling data, lumped hydrological models have been used widely in karst areas (Kurtulus and Razack, 2007; Ladouche et al., 2014). In a lumped model, the river basin is considered as a whole to calculate the runoff generation and confluence, and there is no division running into sub-basins (Dewandel et al., 2003; Bittner et al., 2020). Lumped models usually consider the inputs and outputs of the model (Liedl and Sauter, 2003; Hartmann and Bake, 2013, 2017). 
In addition, most of the model parameters are not optimized in a lumped model, and the physical meaning of each parameter is unclear (Chen, 2009; Bittner et al., 2020).

Distributed hydrological models are of active interest in flood simulation and forecasting research (Ambroise et al., 1996; Beven and Binley, 2006; Zhu and Li, 2014). Compared with a lumped model, a distributed model has a more definite physical significance for the model structure in terms of its mechanism (Meng and Wang, 2010; Epting et al., 2018). In a distributed hydrological model, an entire karst basin can be divided into many sub-basins (Birk et al., 2005) using high-resolution digital elevation map (DEM) data. In the rainfall-runoff algorithm of the model, the hydrogeological conditions and karst aquifer characteristics can be fully considered to precisely simulate the runoff generation and confluence (Gang et al., 2019). The commonly used basin distributed hydrological models (i.e., not a special groundwater numerical model such as MODFLOW) have also been applied widely in karst areas, and include the SHE/MIKE SHE model (Abbott et al., 1986a,b; Doummar et al., 2012), SWMM model (Peterson and Wicks, 2006; Blansett and Hamlett, 2010; Blansett, 2011), TOPMODEL (Ambroise et al., 1996; Suo et al., 2007; Lu et al., 2013; Pan, 2014), and SWAT model (Peterson and Hamlett, 1998; Ren, 2006).

The commonly used distributed hydrological models have multiple structures and numerous parameters (Lu et al., 2013; Pan, 2014), which make distributed model may need vast amounts of data to build its framework in karst regions. For example, the distributed groundwater model MODFLOW-CFPM1 requires detailed data regarding the distribution of karst conduits in a study area (Reimann et al., 2009; Qin and Jiang, 2014). Another example is the Karst-Liuxihe model (Li et al., 2019), which has 5 underground vertical layers in the model structure and has 15 parameters, make it hard to model in karst areas. In addition, a special borehole pumping test may be required to obtain the rock permeability coefficient.

To overcome the difficulty of the large modeling-data demands for distributed hydrological models in karst areas, a new physical model based on distributed hydrological known as the QMG (Qingmuguan) model was developed. This QMG model has a double-layer structure and fewer parameters. The horizontal structure is divided into river channel units and slope units. The vertical structure below the surface is divided into a 
shallow karst aquifer and a deep karst aquifer system. Only a small amount of hydrogeological data is needed for modeling in karst basins.

To ensure that the QMG model work well in karst flood simulation and prediction in the case of relatively simple structure and parameters. We carefully designed the algorithms of runoff generation and confluence in the model. And to verify its applicability of QMG model in flood simulation in karst basins, we selected the Qingmuguan karst trough valley in Chongqing, China, as the study area for a flood simulation and uncertainty analysis. In particular, the sensitivity of model parameters was analyzed.

\section{Study Area and Data}

\subsection{Landform and topography}

The Qingmuguan karst trough valley is located in the southeastern part of the Sichuan Basin, China, at the junction of the Beibei and Shapingba districts in Chongqing, with coordinates of $29^{\circ} 40^{\prime} \mathrm{N} \sim 29^{\circ} 47^{\prime} \mathrm{N}, 106^{\circ} 17^{\prime} \mathrm{E} \sim 106^{\circ} 20^{\prime} \mathrm{E}$. The basin covers an area of 13.4 $\mathrm{km}^{2}$ and is part of the southern extension of the anticline at Wintang Gorge in the Jinyun Mountains, with the anticlinal axis of Qingmuguan located in a parallel valley in eastern Sichuan (Yang et al., 2008). The surface of the anticline is heavily fragmented, and faults are extremely well-developed with large areas of Triassic carbonate rocks exposed. Under the long-term erosion of karst water, a typical karst landform pattern of "three mountains and two troughs" has formed (Liu et al., 2009). Such karst trough landform provides convenient conditions for flood propagation, and the karst landform development is extremely common in the karst region of southwest China, especially in the karst region of Chongqing. Similar regions include the karst trough valley of the Zhongliang Mountains and the Laolongdong karst basin in Nanshan, Chongqing.

The basin is oriented north-north-east and south-south-west in a narrow band of slightly curved arcs and is about $12 \mathrm{~km}$ long from north to south. The direction of the mountains in the region is basically the same as the direction of the tectonic line. The difference in relative elevation is between $200-300 \mathrm{~m}$. Fig. 1 is a map showing an overview of the 
Qingmuguan karst basin.

Figure 1 The Qingmuguan karst basin.

\subsection{Hydrogeological conditions}

The Qingmuguan basin is located within the subtropical humid monsoon climate zone, with an average temperature of $16.5^{\circ} \mathrm{C}$ and a average precipitation of $1250 \mathrm{~mm}$ that is mainly concentrated in May-September. An underground river system has developed in the karst trough valley, with a length of $7.4 \mathrm{~km}$, the water supply of underground river mainly comes from rainfall recharge (Zhang, 2012). Most of the precipitation is collected along the hill slope into the karst depressions at the bottom of the trough valley, where it is recharged to the underground river through the dispersed infiltration of surface karst fissures and concentrated injection from sinkholes (Fig. 1a). An upstream surface river collects in a gentle valley and enters the underground river through the Yankou sinkhole (elevation 524 m). Surface water in the middle and lower reaches of the river system mainly enters the underground river system through catenuliform sinkholes or fissures.

The stratigraphic and lithologic characteristics of the basin are largely dominated by carbonate rocks of the Lower Triassic Jialingjiang Group $\left(\mathrm{T}_{1 \mathrm{j}}\right)$ and Middle Triassic Leikou Slope Group $\left(\mathrm{T}_{21}\right)$ on both sides of the slope, with some quartz sandstone and mudstone outcrops of the Upper Triassic Xujiahe Group $\left(\mathrm{T}_{3 \mathrm{xj}}\right)$ (Zhang, 2012). The topography of the basin presents a general anticline (Fig. 1b), where carbonate rocks on the surface are corroded and fragmented, with a large permeability coefficient. Compared with the core of the anticline, the rocks of the two wings of the anticline are less eroded and form a good waterproof layer.

To investigate the karst conduits distribution in the underground river system, we conducted a tracer test in the study area. The tracer was placed into the Yankou sinkhole and recovered in the Jiangjia spring (Fig. 1a,c). According to the tracer test results (Gou et al., 2010), the karst water-bearing medium in the aquifer was anisotropic, whereas the soluble carbonate rocks were extremely permeable. The karst conduits in the underground river 
were extremely well-developed, and there was a large single-channel underground river. The response time of the underground river to rainfall was very fast, with the peak flow observed at the outlet of Jiangjia spring 6-8 hours after rainfall. The flood peak rose quickly and the duration of the peak flow was short. The underground river system in the study area is dominated by large karst conduits, which is not conducive to water storage in water-bearing media, but is very conducive to the propagation of floods. data; and 3) rainfall data in the basin and water flow data of the underground river. The DEM data was downloaded from a free database on the public Internet, with an initial spatial resolution of $30 \times 30 \mathrm{~m}$. The spatial resolution of landuse and soil types were $1000 \times 1000$ $\mathrm{m}$, and they were also downloaded from the Internet. After considering the applicability of modelling and computational strength, as well as the size of the basin in the study area (13.4 $\mathrm{km}^{2}$ ), the spatial resolution of the three types of data was resampled uniformly in the QMG model and downscaled to $15 \times 15 \mathrm{~m}$ based on a spatial discrete method by Berry et. (2010). A basin survey was conducted to obtain the thickness of the epikarst zone, which was achieved by observing the rock formations on hillsides following cutting for road construction. Information was collected regarding the location, general shape, and size of karst depressions and sinkholes, which had a significant impact on compiling the DEM data and determining the convergence process of surface runoff. 2) Empirical equations developed for similar basins were used to obtain the rainfall infiltration coefficient for different karst landforms and the permeability coefficient of rock. For example, the rock permeability coefficient was calculated based on an empirical equation from a pumping test in a coal mine in the study area (Li et al., 2019). 3) A tracer experiment was conducted in the 
study area (Gou et al., 2010) to obtain information on the underground river direction and flow velocity.

Rainfall and flood data are important model inputs, and represent the driving factors that allow hydrological models to operate. In the study area, rainfall data was acquired by two rain gauges located in the basin (Fig. 1a). Point rainfall was then spatially interpolated into basin-level rainfall (for such a small basin area rainfall results obtained from two rain gauges was considered representative). There were 18 karst flood events in the period of 14 April 2017 to 10 June 2019. We built a rectangular open channel at the underground river outlet and set up a river gauge on it (Fig. 1a) to record the water level and flow data every 15 minutes.

\section{Methodology}

\subsection{Hydrological model} calculation of the underground river system.

The structure of the QMG model is divided into a two-layer structure, both horizontally and vertically. The horizontal structure of the model is divided into river channel units and slope units. The vertical structure below the surface is divided into a shallow karst aquifer (including soil layers, karst fissures, and conduit systems in the epikarst zone) and a deep karst aquifer system (rock stratum and underground river system). This relatively simple model structure makes it need only a small amount of hydrogeological data when modeling in karst regions. Fig. 2 shows a flowchart of the modeling and calculation procedures

Figure 2 Modeling flow chart of QMG (Qingmuguan) model. 
sub-basins are further divided into a lot of karst hydrological response units (KHRUs). The specific steps involved in the division were adopted by referring to studies of hydrological response units (HRUs) in TOPMODEL by Pan (2014). As the smallest basin computing units, the KHRUs can effectively ignore the spatial differences of karst development within the units and reduce the uncertainty in the classification of model units. Fig. 3 shows the spatial structure of the KHRUs.

Figure 3 Spatial structure of the KHRUs (Li et al.,2021). interpolation, and the retention of rainfall and evaporation calculations; 2) runoff generation and confluence calculation for the surface river; and 3) confluence calculation for the underground runoff, including the confluence in the shallow karst aquifer and the underground river system.

\subsubsection{Rainfall and evaporation Calculation}

In the QMG model, the spatial interpolation of rainfall is accomplished by a kriging method using the ArcGIS 10.2 software. The Tyson polygon method may be a simpler method for rainfall interpolation if the number of rainfall gauges in the basin is sufficient. interpolated into areal rainfall for the entire basin.

et al., 2020):

$237\left\{\begin{array}{l}E_{v}=V^{t+\Delta t}-V^{t}-P_{v} \\ E_{\mathrm{s}}=\lambda E_{p}, \text { if } F=F_{c} \\ E_{s}=\lambda E_{p} \frac{F}{F_{c}}, \text { if } F<F_{\text {sat }} \\ E_{\mathrm{w}}=\Delta e \cdot\left[1.12+0.62(\Delta T)^{0.9}\right] \cdot\left[0.084+0.24\left(1-\gamma^{2}\right)^{1 / 2}\right] \cdot\left[0.348+0.5 \omega^{1.8-1.137 \omega^{0.05}}\right]\end{array}\right.$

Here, $E_{v}[\mathrm{~mm}]$ is the vegetal discharge, $V^{t+\Delta t}-V^{t}[\mathrm{~mm}]$ is the rainfall variation 
$[\mathrm{mm}]$ is the actual soil evaporation. The term $\lambda$ is the evaporation coefficient. The term

$E_{p}[\mathrm{~mm}]$ is the evaporation capability, which can be measured experimentally or estimated by the water surface evaporation equation $E_{w}$. The term $F[\mathrm{~mm}]$ is the actual soil moisture, $F_{\text {sat }}[\mathrm{mm}]$ is saturation moisture content, $F_{c}[\mathrm{~mm}]$ is field capacity, $E_{w}$ $[\mathrm{mm} / \mathrm{d}]$ is evaporation of water surface, and $\Delta e=e_{0}-e_{150}[\mathrm{hPa}]$ is the draught head between the saturation vapor pressure of the water surface and the air vapor pressure $150 \mathrm{~m}$ above the water surface $(150 \mathrm{~m}$ above the water surface was selected here because the altitude for temperature and humidity observations in the southwestern karst regions of China is usually set at $150-200 \mathrm{~m})$. The term $\Delta T=t_{0}-T_{150}\left[{ }^{\circ} \mathrm{C}\right]$ is the temperature difference between the water surface and the temperature $150 \mathrm{~m}$ above the water surface, $\gamma$ is the relative humidity $150 \mathrm{~m}$ above the water surface, and $\omega[\mathrm{m} / \mathrm{s}]$ is the wind speed $150 \mathrm{~m}$ above the water surface.

\subsubsection{Runoff Generation}

In the QMG model, the surface runoff generation in river channel units means the rainfall in the river system after deducting evaporation losses. This portion of the runoff will participate in the confluence process directly through the river system, rather than undergoing infiltration. In contrast, the process of runoff generation in slope units is more complex, and its classification is related to the developmental characteristics of surface karst in the basin, rainfall intensity, and soil moisture. For example, when the soil moisture content is already saturated, there is the potential for excess infiltration surface runoff in exposed karst slope units. The surface runoff generation of the KHRUs in the river channel units and slope units can be described by the following equations (modified from Chen, 2009, 2018; Li et al., 2020):

$$
\left\{\begin{array}{l}
P_{r}(t)=\left[P_{i}(t)-E_{p}\right] \frac{L \cdot W_{\max }}{A} \\
R_{\mathrm{si}}=\left(P_{i}-f_{i}\right), P_{i} \geq f_{\max } \\
R_{\mathrm{si}}=0, P_{i}<f_{\max } \\
f_{\max }=\alpha\left(F_{\mathrm{c}}-F\right)^{\beta}+F_{s}
\end{array}\right.
$$

Here, $P_{r}(t)[\mathrm{mm}]$ is the net rainfall (deducting evaporation losses) in the river channel 
of the river channel, $W_{\max }[\mathrm{m}]$ is the maximum width of the river channel selected, and $A$ $\left[\mathrm{m}^{2}\right]$ is the cross-sectional area of the river channel. $R_{\mathrm{si}}$ is termed excess infiltration runoff in the QMG model, [mm]; when the vadose zone is short of water and has not been filled. The infiltration capacity $f_{\max }$ is different in different karst landform units, $\alpha, \beta$ are Holtan model's parameters; and $F_{\mathrm{s}}[\mathrm{mm}]$ is the stable depth of soil water infiltration.

In the KHRUs (Fig. 3), underground runoff is generated primarily from the infiltration of rainwater and direct confluence recharge from sinkholes or skylights. In the QMG model, the underground runoff is calculated by the following equations (modified from Chen, 2018):

$$
\left\{\begin{array}{l}
R_{g}=R_{0} \exp \left(-p t^{m}\right) \\
R_{e}=v_{e} \cdot I_{\mathrm{w}} \cdot z
\end{array}\right.
$$

where

$$
\left\{\begin{array}{l}
\frac{\partial R_{e}}{\partial x}+I_{\mathrm{w}} \cdot z \cdot \frac{\partial F}{\partial t}=R_{\mathrm{r}}-R_{\mathrm{epi}} \\
v_{e}=K \cdot \tan (\alpha), \quad F>F_{\mathrm{c}} \\
v_{e}=0, \quad F \leq F_{\mathrm{c}}
\end{array}\right.
$$

Here, $R_{\mathrm{g}}[\mathrm{mm}]$ is the underground runoff depth (this part of the underground runoff is mainly from the direct confluence supply of the karst sinkholes or skylights in the study area), $R_{0}[\mathrm{~mm}]$ is the average depth of the underground runoff, $p$ and $m$ are attenuation coefficients calculated by conducting a tracer test in the study area, $R_{e}[\mathrm{~L} / \mathrm{s}]$ is the underground runoff generated from rainfall infiltration in the epikarst zone, $I_{w}[\mathrm{~mm}]$ is the width of the underground runoff on the KHRUs, $z[\mathrm{~mm}]$ is the thickness of the epikarst zone, $R_{r}\left[\mathrm{~mm}^{2} / \mathrm{s}\right]$ is the runoff recharge on the KHRUs during period $t, R_{\text {epi }}\left[\mathrm{mm}^{2} / \mathrm{s}\right]$ is the water infiltration from rainfall, $v_{e}[\mathrm{~mm} / \mathrm{s}]$ is the flow velocity of the underground runoff, $K$ $[\mathrm{mm} / \mathrm{s}]$ is the current permeability coefficient, and $\alpha$ is the hydraulic gradient of the underground runoff. If the current soil moisture is less than the field capacity, i.e., $F \leq F_{\mathrm{c}}$, then the vadose zone is not yet full, there will be no underground runoff generation, and 
rainfall infiltration at this time will continue to compensate for the lack of water in the vadose zone until it is full and before runoff is generated.

\subsubsection{Channel Routing and Confluence}

In the QMG model, the calculation of runoff confluence on the KHRUs includes the confluence of surface river channel and underground runoff. There are already many mature and classical algorithms available for calculating the runoff confluence in river channel units and slope units, such as the Saint-Venant equations and Muskingum convergence model. In this study, the Saint-Venant equations were adopted to describe the confluence in the surface river and hill slope units, for which a wave movement equation was adopted to calculate confluence in slope units (Chen, 2009):

$$
\left\{\begin{array}{l}
\frac{\partial Q}{\partial x}+L \frac{\partial h}{\partial t}=q \\
S_{f}-S_{0}=0
\end{array}\right.
$$

where

$$
Q=v h L=\frac{L}{n} h^{\frac{5}{3}} S_{0}^{\frac{1}{2}} .
$$

Here, we customized two variables $a$ and $b$ :

$$
\left\{\begin{array}{l}
a=\left(\frac{n}{L} S_{0}^{-\frac{1}{2}}\right)^{\frac{3}{5}} \\
b=\frac{3}{5}
\end{array}\right.
$$

Equation (7) was substituted into equation (5) and discretized by a finite difference method, giving

$$
\left\{\begin{array}{l}
\frac{\partial Q}{\partial x}+a b Q^{(b-1)} \frac{\partial Q}{\partial t}-q=0 \\
\frac{\Delta t}{\Delta x} Q_{i+1}^{t+1}+a\left(Q_{i+1}^{t+1}\right)^{b}=\frac{\Delta t}{\Delta x} Q_{i}^{t+1}+a\left(Q_{i+1}^{t}\right)^{b}+q_{i+1}^{t+1} \Delta t
\end{array}\right.
$$

The Newton-Raphson method was used for the iterative calculation using equation (8): 


$$
\left[Q_{i+1}^{t+1}\right]^{k+1}=\left[Q_{i+1}^{t+1}\right]^{k}-\frac{\frac{\Delta t}{\Delta x}\left[Q_{i+1}^{t+1}\right]^{k}+a\left(\left[Q_{i+1}^{t+1}\right]^{k}\right)^{b}-\frac{\Delta t}{\Delta x} Q_{i}^{t+1}-a\left(Q_{i+1}^{t}\right)^{b}-q_{i+1}^{t+1} \Delta t}{\frac{\Delta t}{\Delta x}+a b\left(\left[Q_{i+1}^{t+1}\right]^{k}\right)^{b-1}},
$$

where $Q[\mathrm{~L} / \mathrm{s}]$ is the confluence of water flow in slope units, $L[\mathrm{dm}]$ is its runoff width, $h[\mathrm{dm}]$ is the runoff depth, and $q\left[\mathrm{dm}^{2} / \mathrm{s}\right]$ is the lateral inflow on the KHRUs. Here, the friction slope $S_{f}$ equals the hill slope $S_{0}$, and the inertia term and the pressure term in the motion equation of the Saint-Venant equations were ignored. The term $v[\mathrm{dm} / \mathrm{s}]$ is the flow velocity of surface runoff in the slope units as calculated by the Manning equation, $n$ is the roughness coefficient of the slope units, $Q_{i}^{t+1}[\mathrm{~L} / \mathrm{s}]$ is the slope inflow in the KHRU at time $t+1$, and $Q_{i+1}^{t+1}[\mathrm{~L} / \mathrm{s}]$ is the slope discharge in the upper adjacent KHRU at time $t+1$. equation, where a diffusion wave movement equation was adopted, means the inertia term in the motion equation was ignored:

$$
\left\{\begin{array}{l}
\frac{\partial Q}{\partial x}+\frac{\partial A}{\partial t}=q \\
S_{f}=S_{0}-\frac{\partial h}{\partial x}
\end{array}\right.
$$

A finite difference method and the Newton-Raphson method were used for the iterative calculation of the above equation:

$$
\left\{\begin{array}{l}
{\left[Q_{i+1}^{t+1}\right]^{k+1}=\left[Q_{i+1}^{t+1}\right]^{k}-\frac{\frac{\Delta t}{\Delta x}\left[Q_{i+1}^{t+1}\right]^{k}+c\left(\left[Q_{i+1}^{t+1}\right]^{k}\right)^{b}-\frac{\Delta t}{\Delta x} Q_{i}^{t+1}-c\left(Q_{i+1}^{t}\right)^{b}-q_{i+1}^{t+1} \Delta t}{\frac{\Delta t}{\Delta x}+c b\left(\left[Q_{i+1}^{t+1}\right]^{k}\right)^{b-1}}} \\
c=\left(\frac{1}{3600} n \chi^{\frac{2}{3}} S_{f}^{-\frac{1}{2}}\right)^{\frac{3}{5}}
\end{array}\right.
$$

where $Q[\mathrm{~L} / \mathrm{s}]$ is the water flow in surface river channel units, $A\left[\mathrm{dm}^{2}\right]$ is the discharge section area, $c$ is a custom intermediate variable, and $\chi[\mathrm{dm}]$ is the wetted perimeter of the discharge section area.

The underground runoff in the model includes the confluence of epikarst zone and 
underground river. In the epikarst zone, the karst water-bearing media are highly heterogeneous. For example, the crisscrossed karst fissure systems and conduit systems consisted of large corrosion fractures. When rainfall infiltrates into the epikarst zone, water moves slowly through the small karst fissure systems, while it flows rapidly in larger conduits. The key to determining the confluence velocity lies in the width of karst fractures. In the KHRUs (Fig. 3), the 10-cm width of the fracture was used as a threshold value (Atkinson, 1977), meaning that if the fracture width exceeded $10 \mathrm{~cm}$, then the water movement into it was defined as rapid flow; otherwise, it was defined as slow flow. The confluence in the epikarst zone was calculated by the following equation (modified from Beven and Binley, 2006):

$$
Q(t)_{\mathrm{ijk}}=b_{\mathrm{ijk}} \cdot \frac{\Delta h}{\Delta l} R_{i} C_{j} \cdot T(t)_{\text {slow/rapid }}
$$

where

$$
\left\{\begin{array}{l}
T(t)_{\text {slow }}=n r \frac{\rho g R_{i} C_{j} L_{k}}{12 v} \\
T(t)_{\text {rapid }}=\frac{K_{i j}\left(e^{-f_{i j} h_{i j}}-e^{-f_{i j} z_{i j}}\right)}{f_{i j}}
\end{array}\right.
$$

Here, $Q(t)_{i j k}[\mathrm{~L} / \mathrm{s}]$ is the flow confluence in the epikarst zone at time $t, b_{i j k}[\mathrm{dm}]$ is the runoff width, $\frac{\Delta h}{\Delta l}$ is the dimensionless hydraulic gradient, $T(t)_{\text {slow/rapid }}$ is the dimensionless hydraulic conductivity, $\rho[\mathrm{g} / \mathrm{L}]$ is the density of the water flow, $g\left[\mathrm{~m} / \mathrm{s}^{2}\right]$ is gravitational acceleration, $n$ is the valid computational units, $R_{i} C_{j} L_{k}[\mathrm{~L}]$ is the volume of the $i j k$-th KHRU, $v$ is kinematic viscosity coefficient, $f_{i j}$ is the attenuation coefficient in the epikarst zone, $h_{i j}[\mathrm{dm}]$ is the depth of shallow groundwater, and $z_{i j}[\mathrm{dm}]$ is thickness of epikarst zone.

The distinction between rapid and slow flows in the epikarst zone is not absolute. The 10-cm width of a karst fracture as the dividing threshold also has some subjectivity. In fact, there is usually water exchange between the rapid and slow flows at the junction of large and small fissures in karst aquifers. In the QMG model, this water exchange can be described 
with this equation (modified form Li et al., 2021):

$$
\left\{\begin{array}{l}
Q=\alpha_{i, j, k}\left(h_{n}-h_{i, j, k}\right) \\
\alpha_{i, j, k}=\sum_{i p=1}^{n p} \frac{\left(K_{w}\right)_{i, j, k} \pi d_{i p} \frac{1}{2}\left(\Delta l_{i p} \tau_{i p}\right)}{r_{i p}}
\end{array}\right.
$$

Here, $\alpha_{i, j, k}\left[\mathrm{dm}^{2} / \mathrm{s}\right]$ is the water exchange coefficient in the $i j k$-th KHRU,

$355\left(h_{n}-h_{i, j, k}\right)[\mathrm{dm}]$ is the water head difference between the rapid and slow flows at the junction of large and small fissures in KHRUs, $n p$ is the number of fissure systems connected to the adjacent conduit systems, $\left(K_{w}\right)_{i, j, k}[\mathrm{dm} / \mathrm{s}]$ is the permeability coefficient at the junction of a fissure and conduit, $d_{i p}$ and $r_{i p}[\mathrm{dm}]$ are the conduit diameter and radius, respectively, $\Delta l_{i p}[\mathrm{dm}]$ is the length of the connection between conduits $i$ and $p$, and $\tau_{i p}$ is the conduit curvature. Some of the parameters in this equation, such as $\left(K_{w}\right)_{i, j, k}$ and $\left(h_{n}-h_{i, j, k}\right)$, were obtained by conducting an infiltration test in the study area. confluence at the basin outlet. To facilitate the calculation of confluence in the QMG model, the underground river systems can be generalized into large multiple conduit systems. During floods, these conduit systems are mostly under pressure. Whether the water flow is laminar or turbulent depends on the flow regime at that time. The water flow into these conduits is calculated by the Hagen-Poiseuille equation and the Darcy-Weisbach equation (Shoemaker et al., 2008):

$$
\left\{\begin{array}{l}
Q_{\text {laminar }}=-A \frac{g d^{2} \partial h}{32 v \partial x}=-A \frac{\rho g d^{2} \Delta h}{32 \mu \tau \Delta l} \\
Q_{\text {turbulent }}=-2 A \sqrt{\frac{2 g d|\Delta h|}{\Delta l \tau}} \log \left(\frac{H_{c}}{3.71 d}+\frac{2.51 v}{\left.d \sqrt{\frac{2 g d^{3}|\Delta h|}{\Delta l \tau}}\right) \frac{\Delta h}{|\Delta h|}}\right.
\end{array}\right.
$$

Here, $Q_{\text {laminar }}[\mathrm{L} / \mathrm{s}]$ is the water flow of the laminar flow in the conduit systems, $A$ 
$\left[\mathrm{dm}^{2}\right]$ is the conduit cross-sectional area, $d[\mathrm{dm}]$ is the conduit diameter, $\rho\left[\mathrm{kg} / \mathrm{dm}^{3}\right]$ is the density of the underground river, $v=\mu / \rho$ is the coefficient of kinematic viscosity, $\Delta h / \tau \Delta l$ is the hydraulic slope of the conduits, $\tau$ is the dimensionless conduit curvature, $Q_{\text {turbulent }}[\mathrm{L} / \mathrm{s}]$ is the turbulent flow in the conduit systems, and $H_{c}[\mathrm{dm}]$ is the average conduit wall height.

\subsection{Parameter Optimization}

In total, the QMG model has 12 parameters, of which flow direction and slope are topographic parameters that can be determined from the DEM without parametric optimization, while the remaining 10 parameters require calibration. Other distributed hydrological models with multiple structures usually have many parameters. For example, the Karst-Liuxihe model ( $\mathrm{Li}$ et al., 2021) has 15 parameters that need to be calibrated. In the QMG model, each parameter is normalized as

$$
x_{i}=x_{i}^{*} / x_{i 0}
$$

where $x_{i}$ is the dimensionless parameter value $i$ after it is normalized, $x^{*}$ is the parameter value $i$ with an actual physical property, and $x_{i 0}$ is the initial or final value of $x_{i}$. Through the processing of equation (16), the value range of the model parameters is limited to a hypercube $K_{n}=\left(X \mid 0 \leq x_{i} \leq 1, i=1,2, \ldots, n\right)$, which is a dimensionless value. Such a normalized treatment can ignore the influence of the spatiotemporal variation of the underlying surface attributes on the parameters and at the same time simplify the parameter classification and parameter number of the model to a certain extent. Accordingly, the model parameters can be further divided into rainfall-evaporation parameters, epikarst-zone parameters, and underground-river parameters. Table 1 lists the parameters of the QMG model.

Table 1 Parameters of QMG model.

Because the QMG model has relatively few parameters, it is possible to calibrate them manually, which has the advantage that the operation is easy to implement and does not require a special program for parameter optimization. However, the disadvantage is that 
it is subjective, which can lead to great uncertainty in the manual parameter calibration process. To compare the effects of parameter optimization on model performance, this study used both a manual calibration of parameters and the improved chaotic particle swarm algorithm (IPSO) for the automatic calibration of model parameters, and compared the effects of both on flood simulation.

In general, the structure and parameters of a standard particle swarm algorithm (PSO) are simple, with the initial parameter values obtained at random. For parameter optimization in high-dimensional, multi-peak hydrological models, the standard PSO is easily limited to a local convergence and cannot achieve the optimal effect, while the late evolution of the algorithm may also cause problems, such as precocity and stagnant evolution, due to the "inert" aggregation of particles, which seriously affects the efficiency of parameter selection. It is necessary to overcome the above problems and make the algorithm converge to the global optimal solution with a high probability. In parameter optimization for the QMG model, we improved the standard PSO algorithm by adding chaos theory, and developed the IPSO, where 10 cycles of chaotic disturbances were added to improve the activity of the particles. The inverse mapping equation of the chaotic variable is as follows:

$$
\left\{\begin{array}{l}
X_{i j}=X_{\min }+\left(X_{\max }-X_{\min }\right) * Z_{i j} \\
Z_{i j}^{\prime}=(1-\alpha) Z^{*}+\alpha Z_{i j}
\end{array}\right.
$$

where $X_{i j}$ is the optimization variable for the model parameters, $\left(X_{\max }-X_{\min }\right)$ is the difference between its maximum and its minimum, $Z_{i j}$ is the variable before the disturbance is added, and $Z_{i j}^{\prime}$ represents the chaotic variables after a disturbance is added, $\alpha$ is a variable determined by the adaptive algorithm, $0 \leq \alpha \leq 1$, and $Z^{*}$ is the chaotic variable formed when the optimal particle maps to the interval $[0,1]$. In parameter optimization, the flowchart of the IPSO is shown in Fig. 4.

Figure 4 Algorithm flow chart of the IPSO. 


\subsection{Uncertainty Analysis}

As a type of mathematical and physical model, a hydrological model has some uncertainty in flood simulation and forecasting because of the errors in system structure and the algorithm (Krzysztofowicz and Kelly, 2000). A multi-parametric sensitivity analysis method (Choi et al., 1999; Li et al., 2020) was used to analyze the sensitivity of the parameters in the QMG model. Parameter sensitivity analysis steps are as follows.

1) Selection of appropriate objective function

The Nash-Sutcliffe coefficient is widely used as the objective function to evaluate the performance of hydrological models (Li et al., 2020, 2021). It was therefore used to assess the QMG model. Because the most important factor in flood forecasting is the peak discharge, it is used in the Nash coefficient equation:

$$
N S C=1-\frac{\sum_{i=1}^{n}\left(Q_{i}-Q_{i}^{\prime}\right)^{2}}{\sum_{i=1}^{n}\left(Q_{i}-\bar{Q}\right)^{2}},
$$

where NSC is Nash-Sutcliffe coefficient values, $Q_{i}[\mathrm{~L} / \mathrm{s}]$ is the observed flow discharges, $Q_{i}{ }^{\prime}$ $[\mathrm{L} / \mathrm{s}]$ is the simulated discharge, $\bar{Q}[\mathrm{~L} / \mathrm{s}]$ is the average value of the observed discharges, and $n[\mathrm{~h}]$ is the observation period.

2) Parameter sequence sampling

The Monte Carlo sampling method was applied to sample 8,000 groups of parameter sequences. The parametric sensitivity of the QMG model was analyzed and evaluated by comparing the differences between the a priori and a posteriori distributions of the parameters.

\section{3) Parameter sensitivity assessment}

The a priori distribution maens its probability distribution of a model parameter, while the a posteriori distribution can be calculated based on the simulation result of the parametric optimization. If there is a significant difference between them, then the parameter being tested has a high sensitivity, whereas if there is no obvious difference, then the parameter is insensitive. The parametric priori distribution is calculated as follows: 


$$
\left\{\begin{array}{l}
P_{i, j}\left(N S C_{i, j} \geq 0.85\right)=\frac{n}{N+1} \times 100 \\
\sigma_{i}=\sum_{j=1}^{n}\left(P_{i, j}-\overline{P_{i, j}}\right)^{2}
\end{array}\right.
$$

where $P_{i, j}$ is the priori distribution'probability when $N S C_{i, j} \geq 0.85$. We used a

simulated Nash coefficient of 0.85 as the threshold value, and $n$ was the number of occurrences of a Nash coefficient greater than 0.85 in flood simulations. In each simulation, only a certain parameter was changed, while the remaining parameters remained unchanged. If the Nash coefficient of this simulation exceeded 0.85 , then the flood simulation results were considered acceptable. The term $\sigma_{i}$ is the difference between the acceptable value and its mean, which represents the parametric sensitivity $\left(0<\sigma_{i}<1\right)$. The higher the $\sigma_{i}$ value, the more sensitive the parameter. $N$ is the 8,000 parameter sequences, and $\overline{P_{i, j}}$ is the average value of the a priori distribution.

\subsection{Model Setting}

Once the model was built, some of the initial conditions had to be set before running it to simulate and forecast floods, such as basin division, the setting of initial soil moisture, and the assumption of the initial parameter range. 1) In the study area, the entire Qingmuguan karst basin was divided into 893 KHRUs, including 65 surface river units, 466 hill slope units, and 362 underground river units. The division of these units formed the basis for calculating the process of runoff generation and convergence. 2) The initial soil moisture was set to $0-100 \%$ of the saturation moisture content in the basin, and the specific soil moisture before each flood had to be determined by a trial calculation. 3) The waterhead boundary conditions of the groundwater were determined by a tracer test in the basin, where a perennial stable water level adjacent the groundwater-divide was used as the fixed waterhead boundary. The base flow of the underground river was determined to be $35 \mathrm{~L} / \mathrm{s}$ from the perennial average dry season runoff. 4) The range of initial parameters and convergence conditions were assumed before parameter optimization (Figure 4). 5) Parameter optimization and flood simulation validated the performance of the QMG model 
474 in karst basins.

\section{4. Results and Discussion}

\subsection{Parameter Sensitivity Results}

The number of parameters in a distributed hydrological model is generally large, and it is important to perform a sensitivity analysis of each parameter to quantitatively assess the impact of the different parameters on model performance. In the QMG model, each parameter was divided into four categories according to its sensitivity: (i) highly sensitive, (ii) sensitive, (iii) moderately sensitive, and (v) insensitive. In the calibration of model parameters, insensitive ones do not need to be calibrated, which can greatly reduce the amount of calculation and improve the efficiency of model operation.

The flow process in the calibration period (14 April to 10 May 2017) was adopted to calculate the sensitivity of the model parameters, for which the calculation principle was equation (19), and the parameter sensitivity results are calculated in Table 2.

Table 2 Parametric sensitivity results in QMG model.

In Table 2, the value of $\sigma_{i}$ [equation (19)] represents a parameter's sensitivity, and the higher the value, the more sensitive the parameter is. From the results in Table 2, it was found that the rainfall infiltration coefficient, rock permeability coefficient, rock porosity, and the related parameters of soil water content, such as the saturated water content, and field capacity, were sensitive parameters. The order of parameter sensitivity was as follows: infiltration coefficient $>$ permeability coefficient $>$ rock porosity $>$ specific yield $>$ saturated water content $>$ field capacity $>$ flow direction $>$ thickness $>$ slope $>$ Soil coefficient $>$ channel roughness $>$ evaporation coefficient.

In the QMG model, parameters are classified as highly sensitive, sensitive, moderately sensitive, and insensitive according to their influence on the flood simulation results. In Table 4, we divided the sensitivity of model parameters into four levels based on the $\sigma_{i}$ value: 1 ) highly sensitive parameters, $0.8<\sigma_{i}<1$; 2) sensitive parameters, $0.65<\sigma_{i}<0.8$; 

coefficient, rock porosity, and specific yield. The sensitive parameters were the saturated water content, field capacity, and thickness of the epikarst zone. The moderately sensitive parameters were flow direction, slope, and soil coefficient. The insensitive parameters were channel roughness and the evaporation coefficient.

\subsection{Parametric Optimization}

In total, the QMG model has 12 parameters, of which only eight need to be optimized, which is relatively few for distributed models. The parameters of flow direction and slope as well as the insensitive parameters of channel roughness and the evaporation coefficient need not be calibrated, which can improve the convergence efficiency of the model parameter optimization.

In the study area, 18 karst floods during the period of 14 April 2017 to 10 June 2019 were recorded at underground river outlet to validate the effects of the QMG model in karst hydrological simulations. The calibration period was 14 April to 10 May 2017 at the beginning of the flow process, with the remainder of the time being the validation period. In the QMG model, the IPSO algorithm was used to optimize the model parameters. To show the necessity of parameter optimization for the distributed hydrological model, the study specifically compared the flood simulations obtained using the initial parameters of the model (without parameter calibration) and the optimized parameters. Fig. 5 shows the iteration process of parameter optimization for the QMG model.

Figure 5 Iteration process of parametric optimization.

Fig. 5 shows that almost all parameters fluctuated widely at the beginning of the optimization, and then after about 15 iterations of the optimization calculation, most of the linear fluctuations become significantly less volatile, which indicated that the algorithm tended to converge (possibly only locally). When the number of iterations exceeded 25 , all parameters remained essentially unchanged, meaning that the algorithm had converged (at this point there was global convergence). It took only 25 iterations to reach a definite 
convergence of the parameter rates with this IPSO algorithm, which is extremely efficient in terms of the parameter optimization of distributed hydrological models. In previous studies of the parametric optimization for the Karst-Liuxihe model in similar basin areas, 50 automatic parameter optimization iterations were required to reach convergence ( $\mathrm{Li}$ et al., 2021), demonstrating the effectiveness of the IPSO algorithm.

To evaluate the effect of parameter optimization, the convergence efficiency of the algorithm, and more importantly, the parameters after calibration were used to simulate floods. Fig. 6 shows the flood simulation effects.

Figure 6 Flow simulation results of QMG model based on parameter optimization.

Fig. 6 shows that the flows simulated by parameter optimization were better than those simulated by the initial model parameters. The simulated flow processes based on the initial parameters were relatively small, with the simulated peak flows in particular being smaller than the observed values, and there were large errors between the two values. In contrast, the simulated flows produced by the QMG model after parameter optimization were very similar to the observed values, which indicates that calibration of the model parameters is necessary and that there was an improvement in parameter optimization through the use of the IPSO algorithm in this study. In addition, it was found that the flow simulation effect was better in the calibration periods than in the validation periods (Fig. 6).

To compare the results of the flow processes simulation with the initial model parameters and the optimized parameters, six evaluation indices (Nash-Sutcliffe coefficient, correlation coefficient, relative flow process error, flood peak error, water balance coefficient, and peak time error) were applied in this study, and the results are presented in Table 3.

Table 3 Flood simulation evaluation index through parametric optimization.

Table 3 shows that the evaluation indices of the flood simulations after parametric optimization were better than those of the initial model parameters. The average values of the initial parameters for these six indices $0.81,0.74,27 \%, 31 \%, 0.80$, and $5 \mathrm{~h}$, respectively. For the optimized parameters, the average values were $0.90,0.91,16 \%, 14 \%, 0.94$, and $3 \mathrm{~h}$, 
respectively. The flood simulation effects after parameter optimization clearly improved, implying that parameter optimization for the QMG model is necessary, and the IPSO algorithm for parameter optimization is an effective approach that can greatly improve the convergence efficiency of parameter optimization, and also ensure that the model performs well in flood simulations.

\subsection{Model Validation in Flood Simulations}

Following parameter optimization, we simulated the whole flow process (14 April 2017 to 10 June 2019 ) based on the optimized and initial parameters of the QMG model (Fig. 6), which enabled a visual reflection of the model used in the simulation of a long series of flow processes. To reflect the simulation effect of the model for different flood events, we divided the whole flow process into 18 flood events, then used the initial parameters of the model and the optimized parameters, respectively, to verify the model performance in flood simulations. Fig. 7 and Table 4 show the flood simulation effects and their evaluation indices using both the initial and the optimized parameters.

Figure 7 Flood simulation effects based on initial and optimized parameters.

Table 4 Flood simulation indices for model validation.

Fig. 7 shows that the flood simulation results using the initial parameters were smaller than the observed values, and the model performance improved in flood simulations after parameter optimization. The simulated flood processes were in good agreement with observations, and were especially effective for simulating flood peak flows. From flood simulation indices in Table 4, the average water balance coefficient based on the initial parameters was 0.69 , i.e., much less than 1 , indicating that the simulated water in the model was unbalanced. After parameter optimization, the average value was 0.92 , indicating that parameter optimization had a significant impact on the model water balance calculation.

Table 4 shows that the average values of the six indices (Nash-Sutcliffe coefficient, correlation coefficient, relative flow process error, flood peak error, water balance coefficient, and peak time error) for the initial parameters were $0.79,0.74,26 \%, 25 \%, 0.69$, and $5 \mathrm{~h}$, respectively, while for the optimized parameters the average values were $0.92,0.90$, 
$10 \%, 11 \%, 0.92$, and $2 \mathrm{~h}$, respectively. All evaluation indices improved after parameter optimization, with the average values of the Nash coefficient, correlation coefficient, and water balance coefficient increasing by $0.13,0.16$, and 0.23 , respectively. The average values of the relative flow process error, flood peak error, and peak time error decreased by $15 \%, 14 \%$, and $3 \mathrm{~h}$, respectively. These reasonable flood simulation results confirmed that parameter optimization by the IPSO algorithm was necessary and effective for the QMG model.

Compared with the overall flow process simulation shown in Figure 6, each flood process was better simulated by the QMG model (Fig. 7). This was because in the function of the QMG model and its algorithm design, the main consideration was the calculation of the flood process, but the correlation algorithm of the dry season runoff was not described well enough. For example, equations (12)-(15) are the flood convergence algorithm. As a result, the model is not good at simulating other flow processes, such as dry season runoff, leading to a low accuracy in the overall flow process. The next phase of our research will focus on refining the algorithm related to dry season runoff and improving the comprehensive performance of the model.

\subsection{Uncertainty Analysis}

\subsubsection{Assessment and Reduction of Uncertainty}

In general, the uncertainty in model simulations are mainly derived from three aspects of the model: 1) the uncertainty of the model input data, 2) the uncertainty of model structure and the algorithm, and 3) the uncertainty of model parameters. In the practical application of a hydrological model, these three uncertainties are usually interwoven, which leads to the overall uncertainty of the final simulation results (Krzysztofowicz, 2014). Therefore, this study focused on the input data, the model structure, and parameter uncertainty to reduce the overall uncertainty of simulation results.

First, the input data (e.g., rainfall, flood event, and some hydrogeological data) were validated and pre-processed through observations in this study, which substantially reduced the uncertainty. 
Second, we simplified the structure of the QMG model. The model was designed with full consideration of the relationship between the amount of data required to build the model and its performance for flood simulation and forecasting in karst regions, and the model's entire framework was integrated through simple structures and easy-to-implement algorithms, using the concept of distributed hydrological modeling. Conventionally, the extent of uncertainty is increased with the growing complexity of the model structure. We therefore ensured that the structure of the QMG model was simple when it was designed, and the model was divided into surface and underground double layer structures. Such a relatively simple structure made the uncertainty of the model structure reduced largely. In contrast, the underground structure of our previous Karst-Liuxihe model (Li et al., 2021) has five layers, which leads to great uncertainty.

Third, appropriate algorithms for runoff generation and confluence were selected. The design function of different models is different, which leads to great differences in the algorithms used. In the QMG model, most of the rainfall-runoff algorithms used have been validated by the research results of others, and some of them were improved to suit karst flood simulation and forecasting by the QMG model. For example, the algorithm of excess infiltration runoff generation [equation (2)] was an improvement of the version used in the Liuxihe model (Chen, 2009, 2018; Li et al., 2020).

Finally, the algorithm of parameter optimization was improved. Considering the shortcomings of the standard PSO algorithm that tends to reach a local convergence, this study developed the IPSO for parameter optimization by adding chaotic perturbation factors. The flood simulation results after parameter optimization were much better than those of the initial model parameters (Figs. 6 and 7 and Tables 2 and 3), which indicates that parameter optimization is necessary for a distributed hydrological model and can reduce the uncertainty of model parameters.

\subsubsection{Parameter Sensitivity Analysis}

From the results of parameter sensitivity in Table 2, it can be seen that the rainfall infiltration coefficient in the QMG model was the most sensitive parameter. It was the key to 
determining the generation of excess infiltration surface runoff and dividing surface runoff from subsurface runoff. If the rainfall infiltration coefficient was greater than the infiltration capacity, it would generate excess infiltration surface runoff on the exposed karst landforms; otherwise, all rainfall would infiltrate to meet the water deficit in the vadose zone, and then continue to seep down into the underground river system, eventually flowing out of the basin through the underground river outlet. The confluence modes of surface runoff and underground runoff were completely different, resulting in a large difference in the simulated flow results. Therefore, the rainfall infiltration coefficient had the greatest impact on the final flood simulation results.

Other highly sensitive parameters such as the rock permeability coefficient, rock porosity, and specific yield were used as the basis for the division of slow flow in karst fissures and rapid flow in conduits. The division of slow and rapid flows also had a great impact on the discharge at the outlet of the basin. Slow flow plays an important role in water storage in a karst aquifer and is very important for the replenishment of river base flow in the dry season. Rapid flow in large conduit systems dominates of the flood runoff and is the main component of the flood water volume in the flood season.

Parameters related to the soil water content, including the saturated water content, field capacity, and thickness, were sensitive parameters and had a large influence on the flood simulation results. This is because the soil moisture content prior to flooding affects how flood flows rise and when peaks occur. If the soil is already very wet or even saturated before the flooding, the flood will quickly rise to reach a peak, and the process line of the flood peak flow will be sharp and thin. This type of flood process forms easily and can lead to disaster-causing flood events. In contrast, if the soil in the basin is very dry before the flooding, the rainfall will first meet the water shortage of the vadose zone, and after it is replenished the rainfall will infiltrate into the underground river. The flood peak of the river basin outlet is therefore delayed.

The moderately sensitive parameters were flow direction, slope, and the soil coefficient. 
channel roughness and the evaporation coefficient. The amount of water lost by evapotranspiration is very small in the total flood water, and it was therefore the least sensitive parameter in the QMG model.

\section{Conclusions}

This study proposed a new distributed physically based hydrological model, i.e., the QMG model, to simulate floods accurately in karst trough valley. The main conclusions of this paper are as follows.

This QMG model has a high application potential in karst hydrology simulations. Other distributed hydrological models usually have multiple structures, resulting in the need for a large amount of data to build models in karst areas (Kraller et al., 2014). The QMG model has only a double-layer structure, with a clear physical meaning, and a small amount of basic data is needed to build the model in karst areas, such as some necessary hydrogeological data. For example, the distribution and flow direction of underground rivers is required, which can be inferred from a tracer test, leading to a low modeling cost. There were fewer parameters in the QMG model than in other distributed hydrological models, with only 10 parameters that needed to be calibrated.

The flood simulation after parameter optimization was much better than the simulation using the initial model parameters. After parameter optimization, the average value of Nash coefficient, correlation coefficient, and water balance coefficient increased by $0.13,0.16$, and 0.23 , respectively; while the average relative flow process error, flood peak error, and peak time error decreased by $15 \%, 14 \%$, and $3 \mathrm{~h}$, respectively. Parameter optimization is necessary for a distributed hydrological model, and the improvement of the IPSO algorithm in this study was an effective way to achieve this.

In the QMG model, the rainfall infiltration coefficient, $I_{c}$, rock permeability coefficient, $K$, rock porosity, $R_{p}$, and the parameters related to the soil water content were sensitive parameters. The order of parameter sensitivity was: infiltration coefficient > permeability coefficient $>$ rock porosity $>$ specific yield $>$ saturated water content $>$ field capacity $>$ flow direction $>$ thickness $>$ slope $>$ soil coefficient $>$ channel roughness $>$ evaporation 
coefficient.

This QMG model is suitable for karst trough valley basins, where the topography is conducive to the spread of flood water. Whether this model is applicable to other karst areas in non-trough valley regions still needs to be verified in the future studies. In addition, the basin area is very small, where the hydrological similarity between different small basin areas varies greatly (Kong and Rui, 2003). The size of the area to be modeled has a great influence on the choice of model spatial resolution (Chen et al., 2017). Therefore, whether the QMG model is suitable for flood forecasting in large karst basins needs to be determined.

\section{Model development.}

This QMG model presented in this study uses the Visual Basic language programming. The general framework of the model and the algorithm consist of three parts: the modeling approach, the algorithm of rainfall-runoff generation and confluence, and the parameter optimization algorithm. As a free and open source hydrological modeling program (QMG model-V1.0), we provide all modeling packages, including model code, installation package, simulation data package and user manual, free of charge. It is important to note that the model we provide are for scientific research purposes only and should not be used for any commercial purposes. Creative Commons Attribution 4.0 International.

Model installation program can be downloaded from ZENODO, cite as JI LI. (2021, June 16). QMG model-V1.0. Zenodo. http://doi.org/10.5281/zenodo.4964701, and http://doi.org/10.5281/zenodo.4964697 (registration required). User manual can be downloaded from http://doi.org/10.5281/zenodo.4964754.

\section{Code availability.}

All code for the QMG model-V1.0 in this paper are available and free, the code can be downloaded from ZENODO, Cite as JI LI. (2021, June 16). QMG model-V1.0 code (Version v1.0). Zenodo. http://doi.org/10.5281/zenodo.4964709 (registration required).

\section{Data availability.}

All data used in this paper are available, findable, accessible, interoperable, and reusable. The simulation data and modelling data package can be downloaded from http://doi.org/10.5281/zenodo.4964727. The DEM was downloaded from the Shuttle Radar Topography Mission database at http://srtm.csi.cgiar.org. The land use-type data were downloaded from http://landcover.usgs.gov, and the soil-type data were downloaded from http://www.isric.org. These data were last accessed on 15 October 2020.

Author contributions. JIL was responsible for the calculations and writing of the whole 
https://doi.org/10.5194/gmd-2021-120

Preprint. Discussion started: 31 August 2021

(C) Author(s) 2021. CC BY 4.0 License.

731 paper. DY and YJ helped conceive the structure of the model. ZF and JL provided significant

732 assistance in the English translation of the paper. MM provided flow data of the study area.

\section{Competing interests.}

734 The authors declare that they have no conflicts of interest.

735 Acknowledgments.

736 This study was supported by the National Natural Science Foundation of China (41830648),

737 Chongqing Municipal Science and Technology Commission Fellowship Fund

738 (cstc2019yszx-jcyjX0002), and the drought monitoring, analysising and early warning of

739 typical prone-to-drought areas of Chongqing (20C00183). 
Abbott, M. B., Bathurst, J. C., Cunge, J. A., O’Connell, P. E., and Rasmussen, J.: An Introduction to the European HydrologicSystem-System Hydrologue Europeen, 'SHE',

Abbott, M. B., Bathurst, J. C., Cunge, J. A., O’Connell, P. E., and Rasmussen, J.: An

Ambroise, B., Beven, K., and Freer, J.: Toward a generalization of the TOPMODEL concepts: Topographic indices of hydrologic similarity. Water Resources Research, 32, 2135-2145, 1996.

Atkinson, T.C.: Diffuse flow and conduit flow in limestone terrain in the Mendip Hills,

Berry, R.A., Saurel, R., and Lemetayer, O.: The discrete equation method (DEM) for fully compressible, two-phase flows in ducts of spatially varying cross-section. Nuclear Engineering \& Design, 240(11), 3797-3818, 2010.

Beven, K., and Binley, A.: The future of distributed models: Model calibration and uncertainty prediction. Hydrological Processes, 6, 279-298, 2006.

Birk, S., Geyer, T., Liedl, R., and Sauter, M.: Process-based interpretation of tracer tests in carbonate aquifers. Ground Water, 43(3), 381-388, 2005.

Bittner, D., Parente, M.T., Mattis, S., Wohlmuth, B., and Chiogna, G.: Identifying relevant hydrological and catchment properties in active subspaces: An inference study of a lumped karst aquifer model. ADVANCES IN WATER RESOURCES, 135,550-560.

doi: 10.1016/j.advwatres.2019.103472, 2020. 
Blansett, K. L., and Hamlett, J. M.: Challenges of Stormwater Modeling for Urbanized Karst Basins. Pittsburgh, Pennsylvania, an ASABE Meeting Presentation, Paper Number: 1009274. doi:10.13031/2013.29840, 2010.

Blansett, K. L.: Flow, water quality, and SWMM model analysis for five urban karst basins.. (Doctoral dissertation). The Pennsylvania State University,USA, 2011.

Chang, Y., and Liu, L.: A review of hydrological models in karst areas. Engineering investigation, 43,37-44, 2015.

Chen, G.M., Jia, J.Y., and Han, Q.: Research on inertia weight reduction strategy of Particle Swarm optimization algorithm. Journal of Xi'an Jiaotong University, 40(1),53-56, 2006.

Choi, J., Harvey, J. W., and Conklin, M. H.: Use of multi-parameter sensitivity analysis to determine relative importance of factors influencing natural attenuation of mining contaminants. the Toxic Substances Hydrology Program Meeting, Charleston,South Carolina, 1999.

Chen, Y. B.: Liuxihe Model, China Science and Technology Press, Beijing, China, 2009.

Chen, Y., Li, J., and Xu, H.: Improving flood forecasting capability of physically based distributed hydrological models by parameter optimization. Hydrol. Earth Syst. Sci. 20, 375-392. https://doi.org/10.5194/hess-20-375-2016, 2016.

Chen, Y., Li, J., Wang, H., Qin, J., and Dong, L.: Large watershed flood forecasting with high-resolution distributed hydrological model. Hydrol. Earth Syst. Sci. 21, 735-749. https://doi.org/10.5194/hess-21-735-2017, 2017.

Chen, Y.: Distributed Hydrological Models. Springer Berlin Heidelberg, Berlin, Germany. https://doi.org/10.1007/978-3-642-40457-3_23-1, 2018.

Dewandel, B., Lachassagne, P., Bakalowicz, M., Weng, P., and Malki, A.A.: Evaluation of aquifer thickness by analysing recession hydrographs. Application to the Oman ophiolite hard-rock aquifer. Journal of Hydrology, 274,248-269, 2003.

Dubois, E., Doummar, J., Séverin Pistre, S., and Larocque, M.: Calibration of a lumped karst system model and application to the Qachqouch karst spring (Lebanon) under climate 
change conditions. Hydrol. Earth Syst. Sci., 24, 4275-4290. https://doi.org/10.5194/hess-24-4275-2020, 2020.

Doummar, J., Sauter, M., and Geyer, T.: Simulation of flow processes in a large scale karst system with an integrated catchment model (MIKE SHE) - identification of relevant parameters influencing spring discharge. Journal of Hydrology, 426-427, 112-123, 2012.

Epting, J., Page, R.M., and Auckenthaler, A.: Process-based monitoring and modeling of Karst springs-Linking intrinsic to specific vulnerability. Science of the Total Environment, 625, 403-415, 2018.

Fleury, P., Plagnes, V., and Bakalowicz, M.: Modelling of the functioning of karst aquifers with a reservoir model: Application to Fontaine de Vaucluse (South of France). Journal of Hydrology, 345,38-49. http://dx.doi.org/10.1016/j.jhydrol.2007.07.014, 2007b.

Ford, D. C., and Williams, P.W.: Karst geomorphology and hydrology. Wiley, Chichester, England, 2007.

Gang, L., Tong, F.G., and Bin,T.: A Finite Element Model for Simulating Surface Runoff and Unsaturated Seepage Flow in the Shallow Subsurface. Hydrological Processes, 6,102-120. doi: 10.1002/hyp.13564, 2019.

Geyer, T., Birk, S., Liedl, R., and Sauter, M.: Quantification of temporal distribution of recharge in karst systems from spring hydrographs. Journal of Hydrology, 348(30), 452-463, 2008.

Gou, P.F., Jiang, Y.J., Hu, Z.Y., Pu, J.B., and Yang, P.H.: A study of the variations in hydrology and hydrochemistry under the condition of a storm in a typical karst subterranean stream. HYDROGEOLOGY\&ENGINEERING GEOLOGY,37(5),20-25, 2010.

Hartmann, A., and Baker, A.: Progress in the hydrologic simulation of time variant of karst systems-Exemplified at a karst spring in Southern Spain. Advances in Water Resources, 54,149-160, 2013. 
Hartmann, A., Goldscheider, N., Wagener, T., Lange, J., and Weiler, M.: Karst water resources in a changing world: Review of hydrological modeling approaches. Reviews of Geophysics 52: 218-242. doi: 10.1002/2013RG000443, 2014a.

Hartmann, A., and Baker, A.: Modelling karst vadose zone hydrology and its relevance for paleoclimate reconstruction. Earth-Science Reviews, 172, 178-192, 2017.

Hartmann, A.: Experiences in calibrating and evaluating lumped karst hydrological models. London: Geological Society, Special Publications, 2018.

Jukić, D., and Denić-Jukić, V.: Groundwater balance estimation in karst by using a conceptual rainfall-runoff model. Journal of Hydrology, 373, 302-315. http://dx.doi.org/10.1016/j.jhydrol.2009.04.035, 2009.

Kong, F.Z., and Rui, X.F.: Hydrological similarity of catchments based on topography. GEOGRAPHICAL RESEARCH, (06), 709-715, 2003.

Kovács, A., and Sauter, M.: Modelling karst hydrodynamics. In: Goldscheider N, Drew D (eds) Methods in karst hydrogeology, IAH international contributions to hydrogeology; 26,264 p, 2007.

Kovács, A., and Perrochet, P.: A quantitative approach to spring hydrograph decomposition. Journal of Hydrology, 352, 16-29. http://dx.doi.org/10.1016/j.jhydrol.2007.12.009, 2008.

Kurtulus, B., and Razack, M.: Evaluation of the ability of an artificial neural network model to simulate the input-output responses of a large karstic aquifer: the la rochefoucauld aquifer (charente, france). Hydrogeology Journal, 15(2), 241-254, 2007.

Krzysztofowicz, R., and Kelly, K.: Hydrologic uncertainty processor for probabilistic river stage forecasting. Water Resources Research, 36(11),3265-3277, 2000.

Krzysztofowicz, R.: Probabilistic flood forecast: Exact and approximate predictive distributions. Journal of Hydrology, 517(1), 643-651, 2014.

Kraller, G., Warscher, M., Strasser, U., Kunstmann, H., and Franz, H.: Distributed hydrological modeling and model adaption in high alpine karst at regional scale 
(berchtesgaden alps, germany). Springer International Publishing Switzerland. https://doi.org/10.1007/978-3-319-06139-9_8, 2014.

Ladouche, B., Marechal, J. C., and Dorfliger, N.: Semi-distributed lumped model of a karst system under active management. Journal of Hydrology, 509,215-230, 2014.

Li, J., Chen, Y., Wang, H., Qin, J., Li, J., and Chiao, S.: Extending flood forecasting lead time in a large basin by coupling WRF QPF with a distributed hydrological model, Hydrol. Earth Syst. Sci. 21, 1279-1294. https://doi.org/10.5194/hess-21-1279-2017, 2017.

Li, J., Yuan, D., Liu, J., Jiang, Y., Chen, Y., Hsu, K. L., and Sorooshian, S.: Predicting floods in a large karst river basin by coupling PERSIANN-CCS QPEs with a physically based distributed hydrological model. Hydrol. Earth Syst. Sci. 23, 1505-1532. https://doi.org/10.5194/hess-23-1505-2019, 2019.

Li, J., Hong, A., Yuan, D., Jiang,Y., Deng,S., Cao,C., and Liu, J.: A new distributed karst-tunnel hydrological model and tunnel hydrological effect simulations. Journal of Hydrology, 593, 125639. https://doi.org/10.1016/j.jhydrol.2020.125639, 2020.

Li, J., Hong, A., Yuan, D., Jiang,Y., Zhang,Y., Deng,S., Cao,C., Liu, J., and Chen,Y.: Elaborate Simulations and Forecasting of the Effects of Urbanization on Karst Flood Events Using the Improved Karst-Liuxihe Model.CATENA,197,104990. https://doi.org/10.1016/j.catena.2020.104990, 2021.

Liedl, R.., Sauter, M., Huckinghaus, D., Clemens, T., and Teutsch, G.: Simulation of the development of karst aquifers using a coupled continuum pipe flow model. Water Resources Research, 39, 50-57, 2003.

Liu, X., Jiang, Y.J., Ye, M.Y., Yang, P.H., Hu, Z.Y., and Li, Y.Q.: Study on hydrologic regime of underground river in typical karst valley- A case study on the Qingmuguan subterranean stream in Chongqing. CARSOLOGICA SINICA, 28(2),149-154, 2009.

Lu, D. B., Shi, Z. T., Gu, S. X., and Zeng, J. J.: Application of Hydrological Model in the Karst Area. Water-saving irrigation.11, 31-34. doi:1007-4929(2013)11-031-04, 2013. 
Mario, T.P., Daniel, B., Steven, A. M., Gabriele, C., and Barbara, W.: Bayesian calibration and sensitivity analysis for a karst aquifer model using active subspaces. Water Resources Research, 55,342-356. doi: 10.1029/2019WR024739, 2019.

Meng, H.H., and Wang, N.C.: Advances in the study of hydrological models in karst basin. Progress in Geography, 29,1311-1318, 2010.

Pan, H.Y.: Hydrological model and application in karst watersheds. China University of Geosciences. Doctoral Dissertation, Wuhan, China, 2014.

Peterson, E.W., and Wicks, C. M.: Assessing the importance of conduit geometry and physical parameters in karst systems using the storm water management model (SWMM).Journal of Hydrology, 329, 1-2, 294-305, 2006.

Peterson, J.R., and Hamlett, J.M.: Hydrologic calibration of the SWAT model in a basin containing fragipan soils. JAWRA Journal of the American Water Resources Association. doi: 10.1111/j.1752-1688.1998. tb00952.x, 1998.

Petrie, R., Denvil, S., Ames, S.,et al.: Coordinating an operational data distribution network for CMIP6 data, Geosci. Model Dev., 14, 629-644, https://doi.org/10.5194/gmd-14-629-2021, 2021

Qin, J.G., and Jiang, Y.P.: A review of numerical simulation methods for CFP pipeline flow. Groundwater. 3, 98-100, 2014.

Reimann, T., Melissa, E., and Hill.: Modflow-cfp: a new conduit flow process for modflow-2005. Ground Water,47(3),321-325. doi:10.1111/j.1745-6584.2009.00561.x, 2009.

Ren, Q.W.: Water Quantity Evaluation Methodology Based on Modified SWAT Hydrological Modeling in Southwest Karst Area, China University of Geoscience, Wuhan, China, 2006.

Shoemaker, W.B., Cunningham, K.J., and Kuniansky, E.L.: Effects of turbulence on hydraulic heads and parameter sensitivities in preferential groundwater flow layers. 
901

Suo, L.T., Wan, J.W., and Lu, X.W.: Improvement and application of TOPMODEL in karst region. Carsologica Sinica, 26(1), 67-70, 2007.

Williams, P. W.: Book Review: Methods in Karst Hydrogeology, Nico Goldscheider and David Drew (eds). Hydrogeology Journal, 17,1025-1025, 2009.

Worthington, S., Ford, D., and Beddows, P.: Porosity and permeability enhancement in unconfined carbonate aquifers as a result of solution. Speleogenesis: evolution of karst aquifers, 2000 .

Yang, P. H., Luo, J.Y., Peng, W., Xia, K.S., and Lin, Y.S.: Application of online technique in tracer test-A case in Qingmuguan subterranean river system, Chongqing, China. CARSOLOGICA SINICA, 27(3),215-220, 2008.

Yu, D., Yin, J., Wilby, R.L., Stuart, N. L., Jeroen, C., Lin, N., Liu, M., Yuan, H., Chen, J., Christel, P., Guan, M., Avinoam, B., Charlie, W. D., Tang, X., Yu, L., and Xu, S.: Disruption of emergency response to vulnerable populations during floods. Nature Sustainability, 3, 728-736. https://doi.org/10.1038/s41893-020-0516-7, 2020.

Yu, Q., Yang, P.H., Yu, Z.L., Chen, X.B., and Wu, H.: Dominant factors controlling hydrochemical variationg of karst underground river in different period, Qingmuguan,Chongqing. CARSOLOGICA SINICA, 35(2),134-143, 2016.

Zhang, Q.: Assesment on the intrinsic vulnerability of karst groundwater source in the Qingmuguan karst valley. CARSOLOGICA SINICA, 31(1),67-73, 2012.

Zhu, C., and Li, Y.: Long-Term Hydrological Impacts of Land Use/Land Cover Change From 1984 to 2010 in the Little River Basin, Tennessee. International Soil and Water Conservation Research, 2(2), 11-21, 2014. 
Table 1 Parameters of the QMG model.

\begin{tabular}{ccc}
\hline Parameters & Variable name & Physical property \\
\hline Infiltration coefficient & $I_{c}$ & Meteorology \\
Evaporation coefficient & $\lambda$ & Vegetation cover \\
\hline Soil thickness & $h$ & Karst aquifer \\
Soil coefficient & $S_{b}$ & Soil type \\
Saturated water content & $S_{c}$ & Soil type \\
Rock porosity & $R_{p}$ & Karst aquifer \\
Field capacity & $F_{c}$ & Soil type \\
Permeability coefficient & $K$ & Karst aquifer \\
\hline Flow direction & $F_{d}$ & Landform \\
Slope & $S_{0}$ & Landform \\
Specific yield & $S_{y}$ & Karst aquifer \\
Channel roughness & $n$ & Landform \\
\hline
\end{tabular}

Table 2 Parametric sensitivity results in QMG model.

\begin{tabular}{cccccc}
\hline $\begin{array}{c}\text { Infiltration } \\
\text { coefficient } / I_{c}\end{array}$ & $\begin{array}{c}\text { Evaporation } \\
\text { coefficient } / \lambda\end{array}$ & Thickness $/ h$ & $\begin{array}{c}\text { Soil } \\
\text { coefficient } / S_{b}\end{array}$ & $\begin{array}{c}\text { Saturated water } \\
\text { content } / S_{c}\end{array}$ & $\begin{array}{c}\text { Specific } \\
\text { yield } / S_{y}\end{array}$ \\
\hline 0.92 & 0.24 & 0.71 & 0.58 & 0.8 & 0.83 \\
\hline $\begin{array}{c}\text { Flow } \\
\text { direction } / F_{d}\end{array}$ & Slope $/ S_{0}$ & $\begin{array}{c}\text { Rock } \\
\text { porosity } / R_{p}\end{array}$ & $\begin{array}{c}\text { Field } \\
\text { capacity } / F_{c}\end{array}$ & $\begin{array}{c}\text { Permeability } \\
\text { coefficient } / K\end{array}$ & $\begin{array}{c}\text { Channel } \\
\text { roughness } / n\end{array}$ \\
\hline 0.74 & 0.68 & 0.86 & 0.78 & 0.89 & 0.36 \\
\hline
\end{tabular}

Table 3 Flood simulation evaluation index through parametric optimization.

\begin{tabular}{cccccccc}
\hline $\begin{array}{c}\text { Parameter } \\
\text { optimization }\end{array}$ & $\begin{array}{c}\text { Parameter } \\
\text { types }\end{array}$ & $\begin{array}{c}\text { Nash } \\
\text { coefficient }\end{array}$ & $\begin{array}{c}\text { Correlation } \\
\text { coefficient }\end{array}$ & $\begin{array}{c}\text { Relative } \\
\text { flow } \\
\text { process } \\
\text { error/\% }\end{array}$ & $\begin{array}{c}\text { Flood } \\
\text { peak } \\
\text { error/\% }\end{array}$ & $\begin{array}{c}\text { Water } \\
\text { balance } \\
\text { coefficient }\end{array}$ & $\begin{array}{c}\text { Peak } \\
\text { time } \\
\text { error } \\
\text { (hours) }\end{array}$ \\
\hline $\begin{array}{c}\text { calibration } \\
\text { periods }\end{array}$ & $\begin{array}{c}\text { initial } \\
\text { optimized }\end{array}$ & 0.82 & 0.77 & 24 & 29 & 0.82 & 4 \\
validation & initial & 0.79 & 0.94 & 14 & 12 & 0.95 & 2 \\
periods & optimized & 0.88 & 0.87 & 18 & 16 & 0.92 & 3 \\
\hline average & initial & 0.81 & 0.74 & 27 & 31 & 0.80 & 5 \\
value & optimized & 0.90 & 0.91 & 16 & 14 & 0.94 & 3 \\
\hline
\end{tabular}


https://doi.org/10.5194/gmd-2021-120

Preprint. Discussion started: 31 August 2021

(c) Author(s) 2021. CC BY 4.0 License.

Table 4 Flood simulation indices for model validation.

\begin{tabular}{|c|c|c|c|c|c|c|c|}
\hline Floods & $\begin{array}{l}\text { Parameter } \\
\text { types }\end{array}$ & $\begin{array}{c}\text { Nash } \\
\text { coefficient }\end{array}$ & $\begin{array}{l}\text { Correlation } \\
\text { coefficient }\end{array}$ & $\begin{array}{c}\text { Relative } \\
\text { flow } \\
\text { process } \\
\text { error } \%\end{array}$ & $\begin{array}{c}\text { Flood } \\
\text { peak } \\
\text { error/\% }\end{array}$ & $\begin{array}{c}\text { Water } \\
\text { balance } \\
\text { coefficient }\end{array}$ & $\begin{array}{c}\text { Peak } \\
\text { time } \\
\text { error/ } \\
\text { (hours) }\end{array}$ \\
\hline \multirow{2}{*}{2017042408} & initial & 0.77 & 0.7 & 28 & 29 & 0.71 & -5 \\
\hline & optimized & 0.95 & 0.89 & 11 & 15 & 0.88 & -2 \\
\hline \multirow{2}{*}{2017050816} & initial & 0.78 & 0.71 & 19 & 19 & 0.76 & -4 \\
\hline & optimized & 0.92 & 0.88 & 11 & 9 & 0.94 & -2 \\
\hline \multirow{2}{*}{2017061518} & initial & 0.76 & 0.6 & 25 & 32 & 0.63 & -5 \\
\hline & optimized & 0.91 & 0.93 & 12 & 11 & 0.95 & -3 \\
\hline \multirow{2}{*}{2017071015} & initial & 0.78 & 0.82 & 25 & 37 & 0.64 & -4 \\
\hline & optimized & 0.92 & 0.87 & 8 & 7 & 0.94 & -2 \\
\hline \multirow{2}{*}{2017091512} & initial & 0.81 & 0.62 & 21 & 16 & 0.78 & -5 \\
\hline & optimized & 0.9 & 0.92 & 13 & 10 & 0.9 & -4 \\
\hline \multirow{2}{*}{2017100815} & initial & 0.75 & 0.68 & 30 & 26 & 0.62 & -2 \\
\hline & optimized & 0.94 & 0.86 & 11 & 15 & 0.92 & -1 \\
\hline \multirow{2}{*}{2018052016} & initial & 0.78 & 0.68 & 25 & 21 & 0.67 & 5 \\
\hline & optimized & 0.91 & 0.93 & 10 & 13 & 0.94 & 2 \\
\hline \multirow{2}{*}{2018060815} & initial & 0.82 & 0.79 & 27 & 22 & 0.69 & -6 \\
\hline & optimized & 0.9 & 0.92 & 11 & 12 & 0.93 & -4 \\
\hline \multirow{2}{*}{2018071212} & initial & 0.84 & 0.75 & 26 & 24 & 0.61 & 5 \\
\hline & optimized & 0.91 & 0.88 & 8 & 15 & 0.92 & 3 \\
\hline \multirow{2}{*}{2018081512} & initial & 0.71 & 0.78 & 26 & 24 & 0.78 & -4 \\
\hline & optimized & 0.89 & 0.94 & 12 & 11 & 0.89 & -3 \\
\hline \multirow{2}{*}{2018090516} & initial & 0.85 & 0.68 & 28 & 23 & 0.68 & -5 \\
\hline & optimized & 0.93 & 0.87 & 12 & 10 & 0.92 & -2 \\
\hline \multirow{2}{*}{2018092514} & initial & 0.79 & 0.78 & 23 & 19 & 0.59 & 5 \\
\hline & optimized & 0.88 & 0.88 & 9 & 11 & 0.89 & 2 \\
\hline \multirow{2}{*}{2018101208} & initial & 0.78 & 0.81 & 28 & 25 & 0.63 & 5 \\
\hline & optimized & 0.92 & 0.94 & 11 & 10 & 0.94 & 2 \\
\hline \multirow{2}{*}{2018111208} & initial & 0.79 & 0.81 & 25 & 24 & 0.65 & -6 \\
\hline & optimized & 0.94 & 0.86 & 13 & 12 & 0.92 & -2 \\
\hline \multirow{2}{*}{2019042512} & initial & 0.78 & 0.8 & 26 & 36 & 0.8 & 5 \\
\hline & optimized & 0.89 & 0.94 & 9 & 16 & 0.93 & 2 \\
\hline \multirow{2}{*}{2019051513} & initial & 0.84 & 0.77 & 32 & 27 & 0.79 & 4 \\
\hline & optimized & 0.91 & 0.88 & 9 & 13 & 0.95 & 2 \\
\hline \multirow{2}{*}{2019052516} & initial & 0.74 & 0.75 & 29 & 26 & 0.63 & -5 \\
\hline & optimized & 0.92 & 0.86 & 7 & 15 & 0.96 & -2 \\
\hline \multirow{2}{*}{2019060518} & initial & 0.85 & 0.83 & 28 & 25 & 0.78 & -4 \\
\hline & optimized & 0.95 & 0.96 & 10 & 12 & 0.92 & -2 \\
\hline \multirow{2}{*}{$\begin{array}{c}\text { average } \\
\text { value }\end{array}$} & initial & 0.79 & 0.74 & 26 & 25 & 0.69 & 5 \\
\hline & optimized & 0.92 & 0.9 & 10 & 11 & 0.92 & 2 \\
\hline
\end{tabular}


https://doi.org/10.5194/gmd-2021-120

Preprint. Discussion started: 31 August 2021

(c) Author(s) 2021. CC BY 4.0 License.

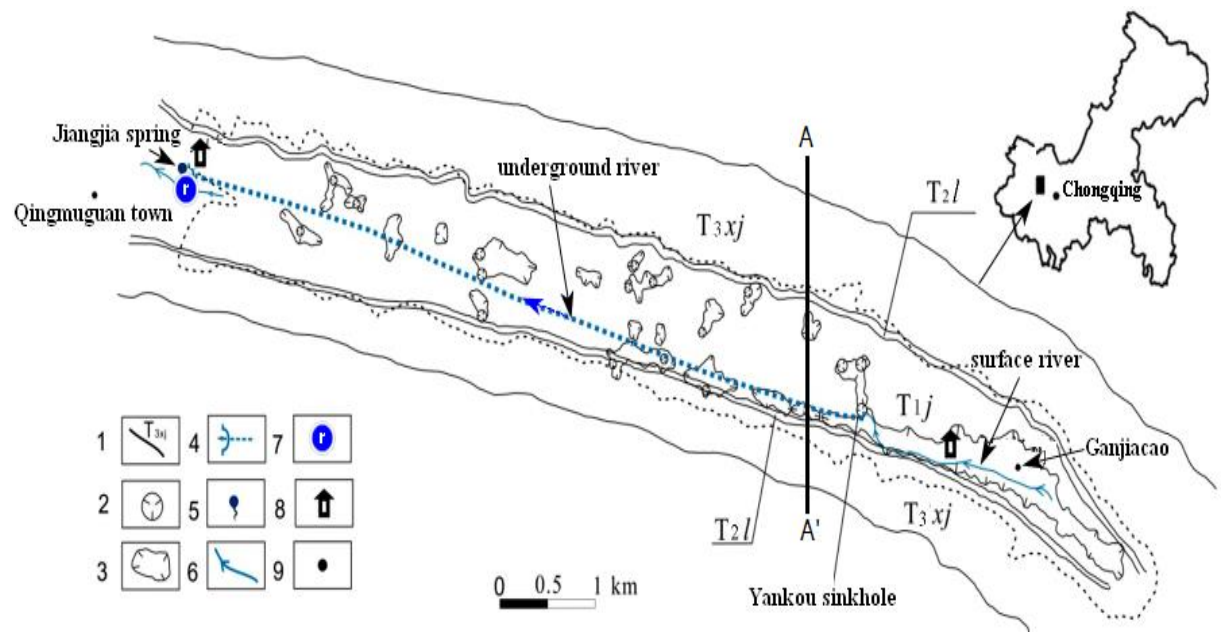

1- stratigraphic boundary, 2-sinkhole, 3- karst depression, 4- underground river, 5karst spring, 6-surface river, 7-river gauge, 8-rain gauge, and 9- geographical name

a. Qingmuguan karst basin (modified from Yu et al.,2016)

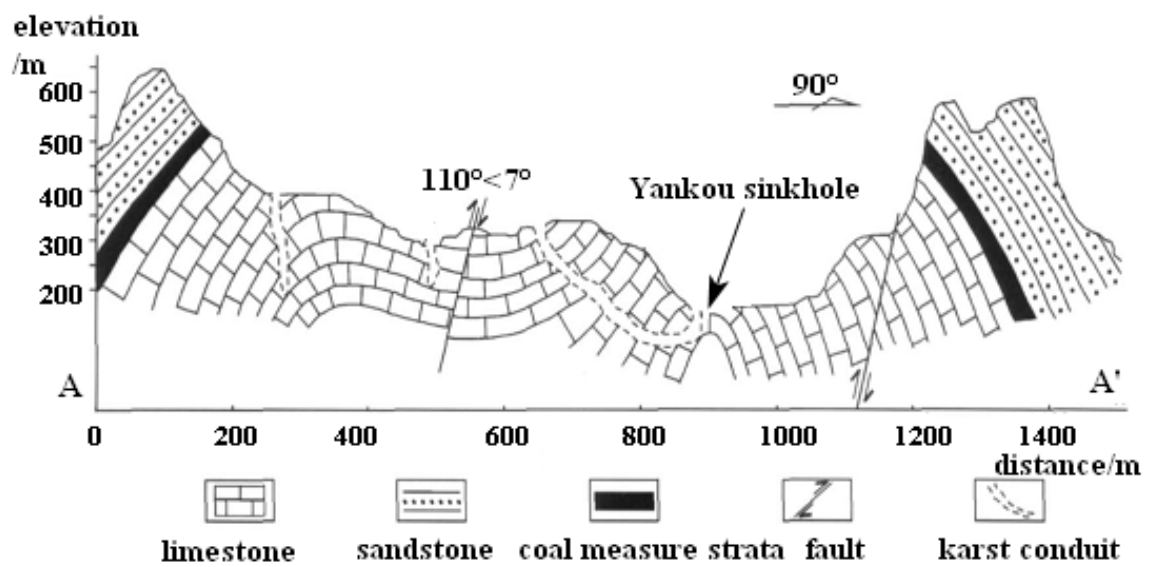

b. Lithologic cross section of Yankou sinkhole/AA'(modified from Zhang,2012) 
elevation
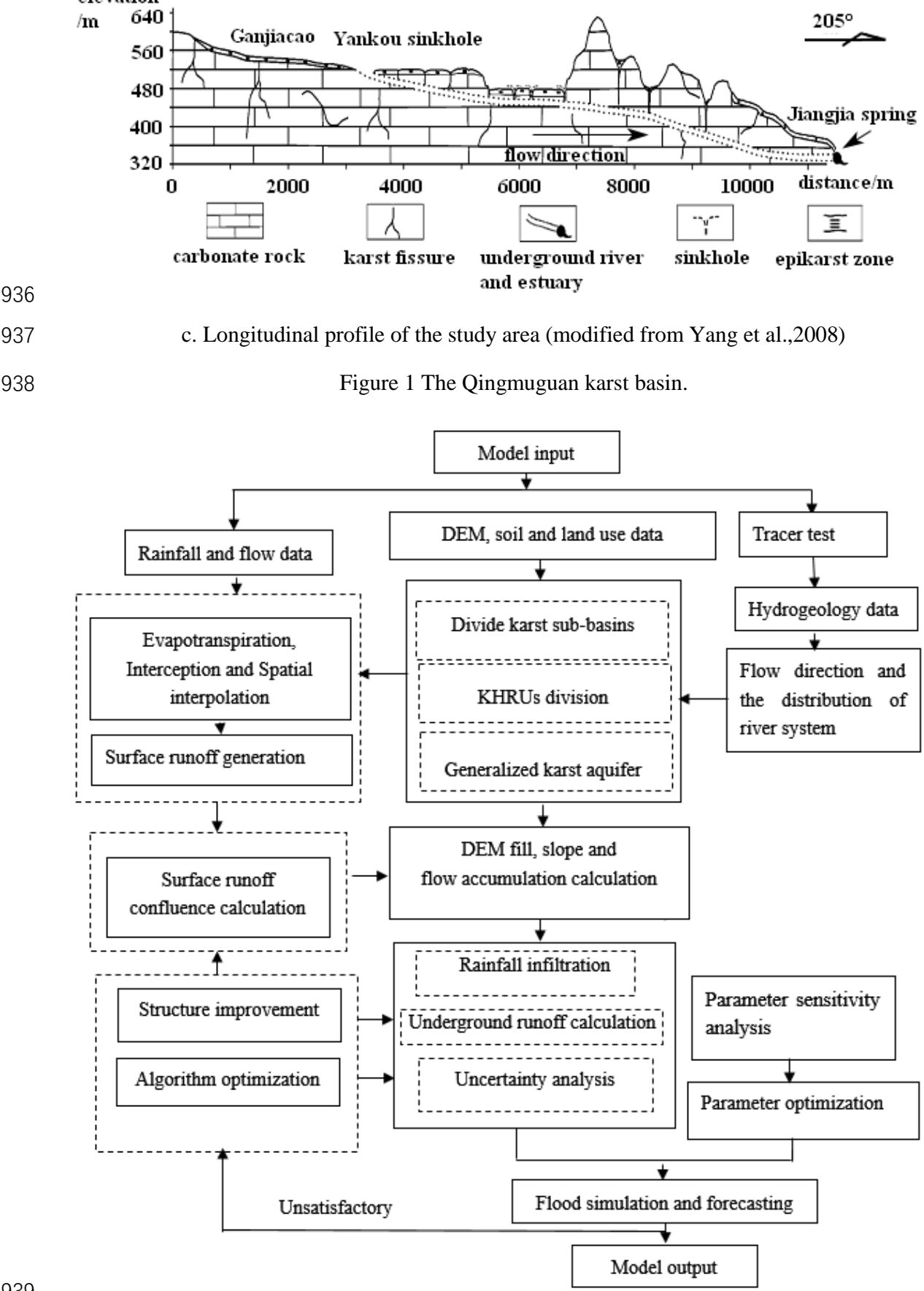

Figure 2 Modeling flow chart of QMG (Qingmuguan) model. 
https://doi.org/10.5194/gmd-2021-120

Preprint. Discussion started: 31 August 2021

(c) Author(s) 2021. CC BY 4.0 License.

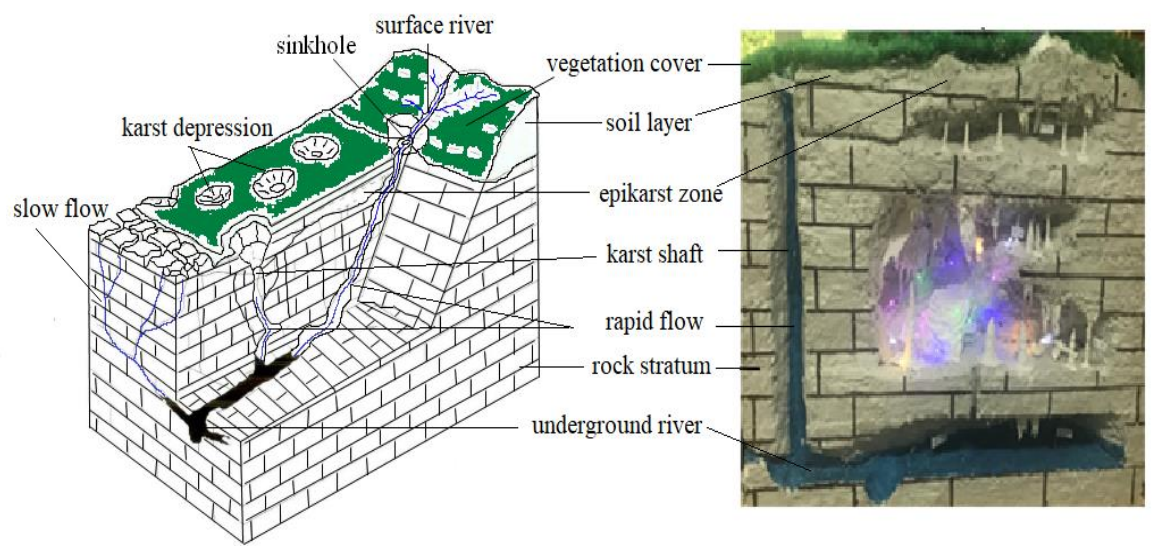

Figure 3 Spatial structure of the KHRUs (Li et al.,2021).

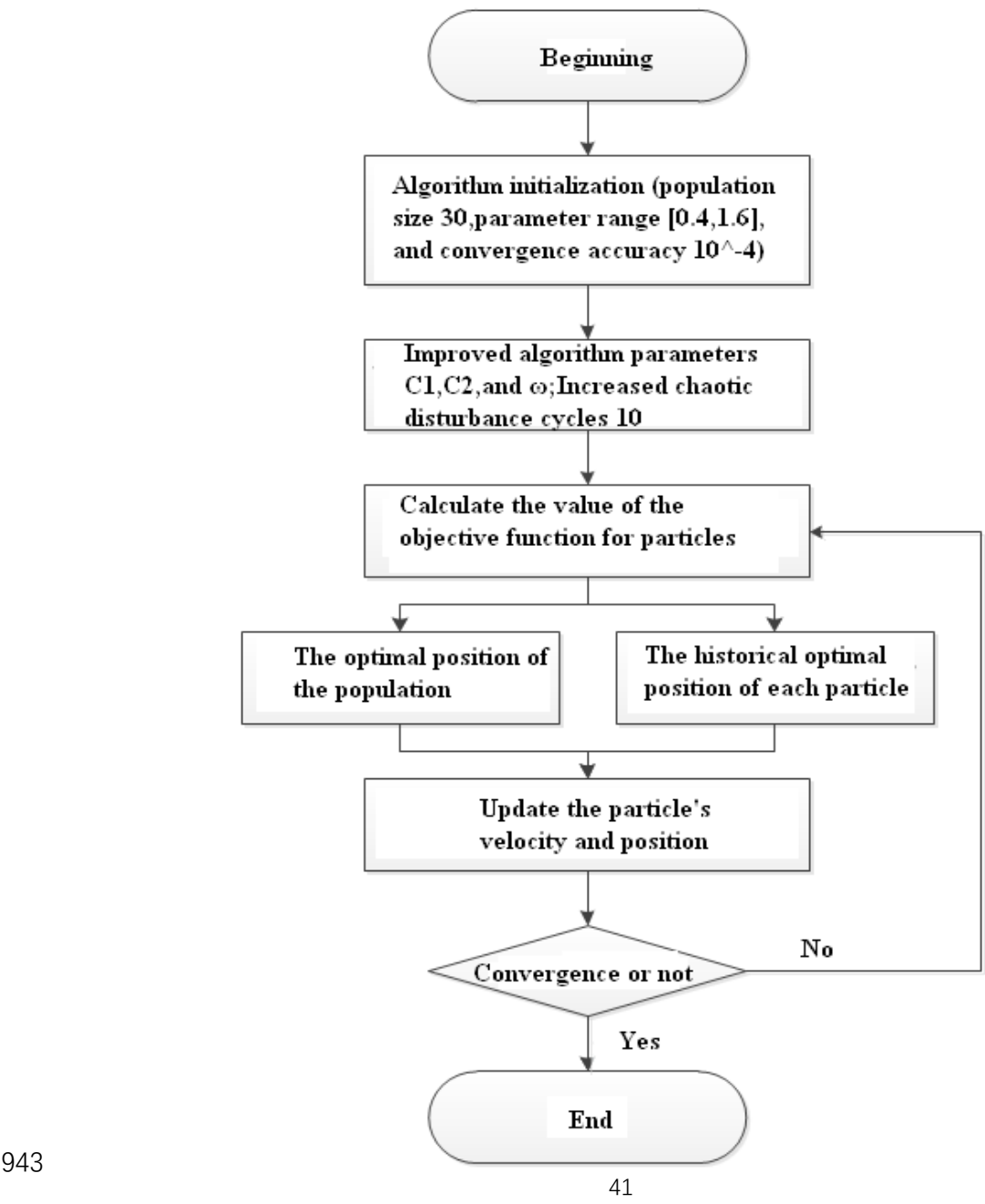


Figure 4 Algorithm flow chart of the IPSO.
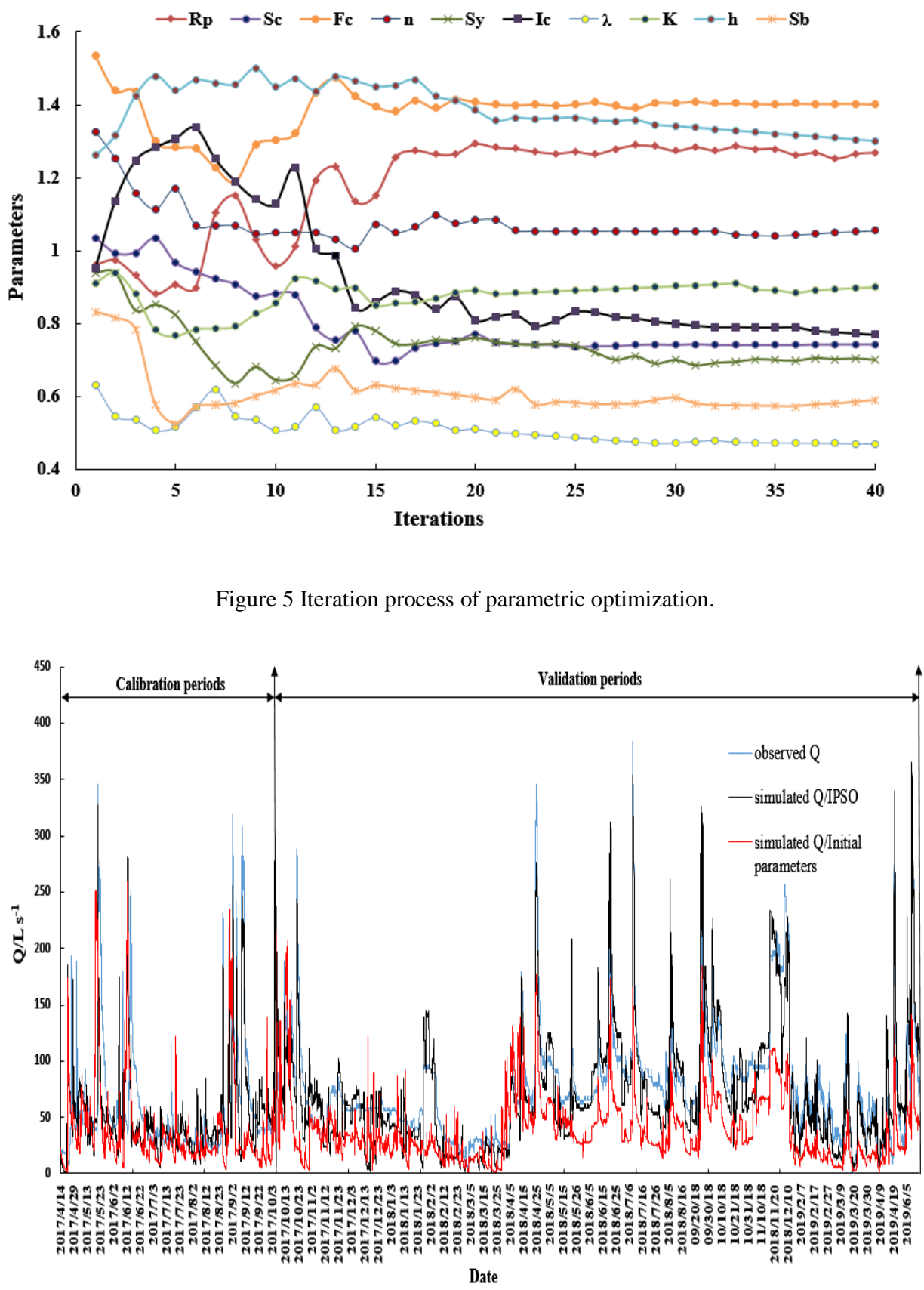

948 Figure 6 Flow simulation results of QMG model based on parameter optimization. 

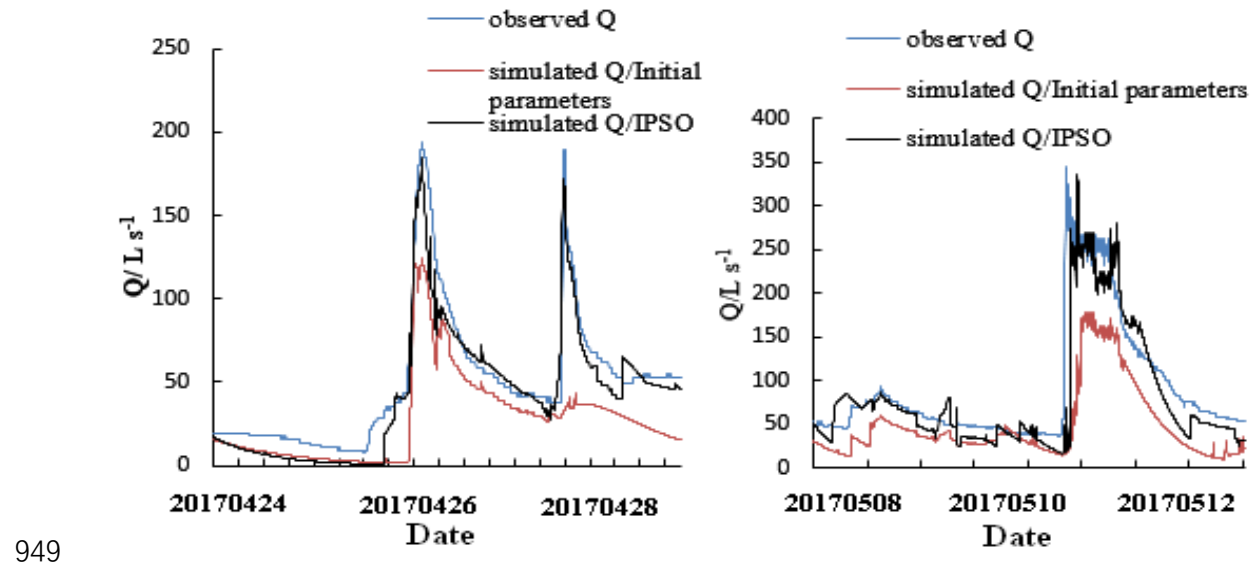

b. flood 201705081600
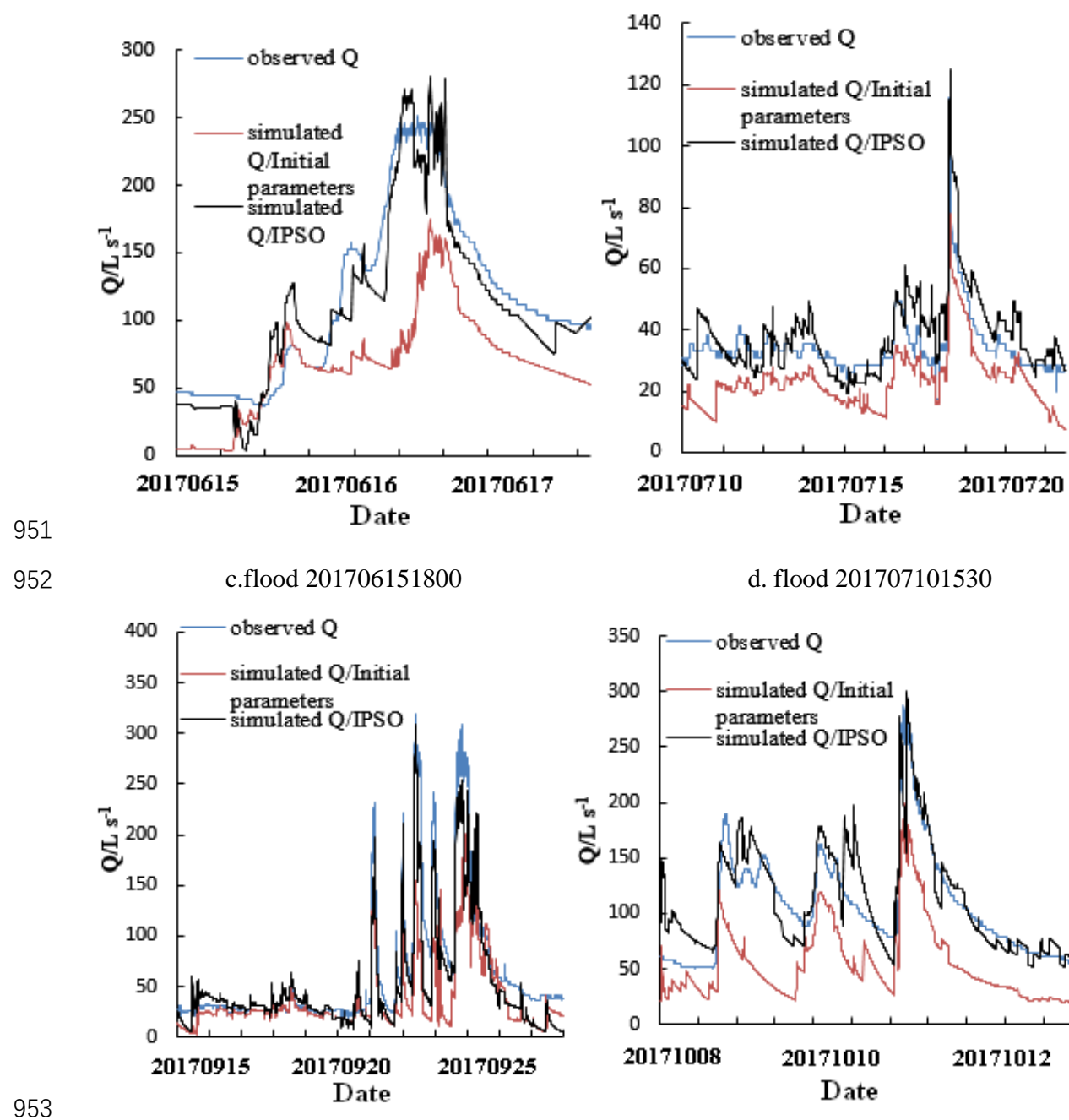
https://doi.org/10.5194/gmd-2021-120

Preprint. Discussion started: 31 August 2021

(c) Author(s) 2021. CC BY 4.0 License.
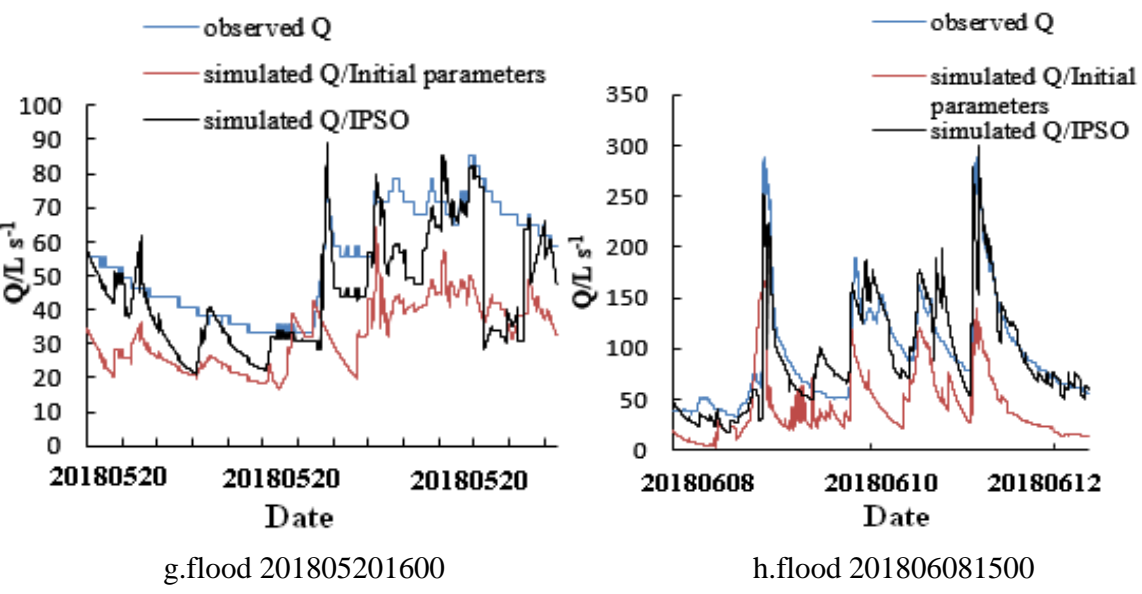

955

g.flood 201805201600

h.flood 201806081500

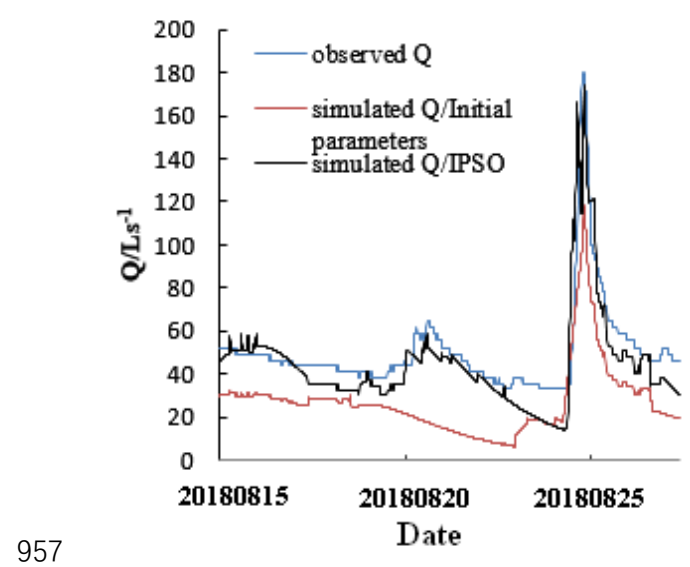

958

959

i.flood 201808151200

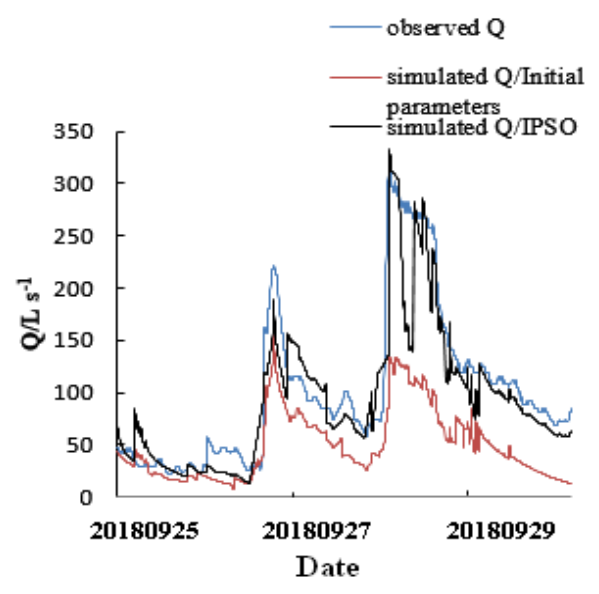

j.flood 201905251600

Figure 7 Flood simulation effects based on initial and optimized parameters. 